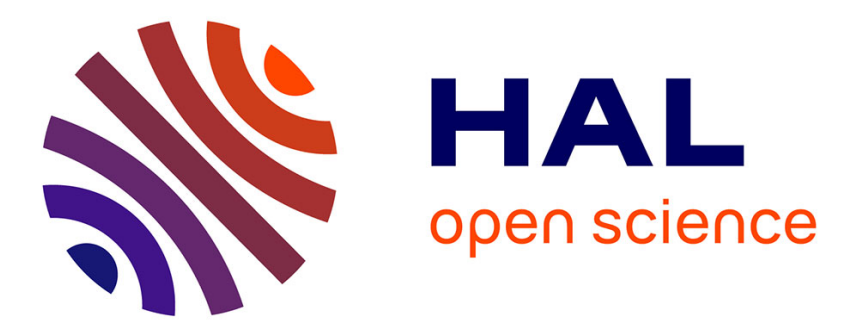

\title{
Interaction between near-annual and ENSO modes in a CGCM simulation: role of equatorial background mean state
}

Boris Dewitte, Carole Cibot, Claire Périgaud, Soon-Il An, Laurent Terray

\section{- To cite this version:}

Boris Dewitte, Carole Cibot, Claire Périgaud, Soon-Il An, Laurent Terray. Interaction between nearannual and ENSO modes in a CGCM simulation: role of equatorial background mean state. Journal of Climate, 2007, 20, pp. $\mathrm{N}^{\circ} 6,1035-1052$. 10.1175/JCLI4060.1 . hal-00280342

\section{HAL Id: hal-00280342 \\ https://hal.science/hal-00280342}

Submitted on 10 Jun 2021

HAL is a multi-disciplinary open access archive for the deposit and dissemination of scientific research documents, whether they are published or not. The documents may come from teaching and research institutions in France or abroad, or from public or private research centers.
L'archive ouverte pluridisciplinaire HAL, est destinée au dépôt et à la diffusion de documents scientifiques de niveau recherche, publiés ou non, émanant des établissements d'enseignement et de recherche français ou étrangers, des laboratoires publics ou privés. 


\title{
Interaction between Near-Annual and ENSO Modes in a CGCM Simulation: Role of the Equatorial Background Mean State
}

\author{
BORIS DEWITTE \\ Laboratoire d'Etude en Géophysique et Océanographie Spatiale, Toulouse, France \\ Carole Cibot \\ Climate Change and Climate Modeling Team, CERFACS/CNRS, SUC-URA1875, Toulouse, France \\ Claire Périgaud \\ Jet Propulsion Laboratory, Pasadena, California \\ SOON-IL AN \\ IPRC, University of Hawaii at Manoa, Honolulu, Hawaii \\ LAURENT TERRAY \\ Climate Change and Climate Modeling Team, CERFACS/CNRS, SUC-URA1875, Toulouse, France
}

(Manuscript received 29 July 2005, in final form 30 May 2006)

\begin{abstract}
A 260-yr-long coupled general circulation model (CGCM) simulation is used to investigate the interaction between ENSO mode and near-annual variability and its sensitivity to the equatorial background mean stratification and seasonal cycles. Although the thermocline mean vertical structure of the model favors the high-order baroclinic modes that are associated with the slow time scales of the coupled variability, the simulated ENSO oscillates at a dominant quasi-biennial frequency. Biases of the climatological velocity field are favorable to the dominance of the zonal advective feedback over the thermocline feedback, the model exhibiting an overenergetic westward seasonal zonal current in the central-western equatorial Pacific, and an upwelling rate that is about half the observations. This sets the conditions for the enhancement of a near-annual mode that is observed to oscillate at an 8-month period in the model. Using an intermediate coupled model of the tropical Pacific where the climatological fields are prescribed to the ones derived from the CGCM, it is demonstrated that the quasi-biennial ENSO variability simulated by the CGCM is mostly due to the biases in the climatological currents of the CGCM. These biases favor the dominance of the fast "zonal advective feedback" over the slow "thermocline feedback" in the coupled system and enhance a fast coupled basin mode. This fast mode differs from the theoretical Pacific Ocean basin mode in that, besides mean temperature advection by the zonal current anomalies, it is also driven by anomalous temperature advection by the total current. Results suggest that the near-annual mode destabilizes the ENSO mode to produce overenergetic quasi-biennial oscillations in the model. It also contributes to the ENSO asymmetry and the cold bias of the CGCM mean state by nonlinear accumulation of temperature zonal advection, which works toward the cold in the western Pacific more than the warm in the east. It is suggested that the model equilibrium results from the interaction between the ENSO mode, the near-annual mode, and the mean state.
\end{abstract}

\section{Introduction}

Although the El Niño-Southern Oscillation (ENSO) is one of the most important sources of interannual

Corresponding author address: Dr. Boris Dewitte, Laboratoire d'Etude en Géophysique et Océanographie Spatiale (LEGOS), 14 av. Edouard Belin, 31401 Toulouse CEDEX 4, France.

E-mail: boris.dewitte@cnes.fr variability in the natural climate system (Philander 1990), the frequency spectrum of the interannual variability in the equatorial Pacific is rather broad and not restrained to the 3-5-yr ENSO cycle. The equatorial coupled system is first forced by uncoupled atmospheric "noise" on monthly or seasonal mean time scales that has the effect of significantly broadening the spectral peak of ENSO (Kirtman and Schopf 1998;

DOI: 10.1175/JCLI4060.1

(C) 2007 American Meteorological Society 
Blanke et al. 1997). In addition, coherent ocean-atmosphere coupled modes can exist at a variety of time scales, going from near-annual (Jin et al. 2003), quasibiennial (Ropelewski et al. 1992), to decadal to interdecadal (Tourre et al. 1999; Zhang et al. 1999).

It is then striking that the variability in most coupled models does not display such a rich spectrum (AchutaRao and Sperber 2002). In addition, despite differences in subgrid parameterizations and resolution, most global coupled general circulation models (CGCMs) produce ENSO occurring at a higher frequency than observed with usually a dominant peak for sea surface temperature anomalies (SSTAs) in the central-eastern equatorial Pacific in the quasi-biennial band (AchutaRao et al. 2004; Guilyardi et al. 2004; Rodgers et al. 2004).

Why then is the quasi-biennial band favored in most CGCMs?

Given the argument that the OGCM usually correctly resolves the equatorial wave dynamics, which are associated with fixed time scales associated to the traveling of Kelvin and Rossby waves back and forth across the Pacific, the atmospheric component may have a role for setting the periodicity of ENSO (Guilyardi et al. 2004). For instance, changes in the longitudinal location of the maximum variability for equatorial wind stress may explain the change of the ENSO frequency at decadal time scales (An and Wang 2000). However, from the early theoretical work by Hirst (1986), it is known that ENSO time scales is to a large extent set by the coupled instabilities that are themselves highly dependent of the background oceanic state (Federov and Philander 2001). Thus, the simpler models in which the climatology is prescribed from observations (or from the derived product), although usually with a less-rich power spectrum for SSTAs, usually exhibit a more realistic dominant frequency of the simulated ENSO variability, suggesting that biases of the simulated tropical Pacific mean state or the seasonal cycle in the CGCM may be responsible for the unrealistic ENSO frequency in most CGCMs.

In theory, modes of variability from near-annual to interannual time scales can be sustained in the tropical Pacific (Jin 1997; An and Jin 2001). Kang et al. (2004) recently demonstrated that the background state determines the prevalence of the "slow" ENSO mode over a "fast" near-annual mode, the latter being related to the theoretical coupled Pacific Ocean basin (POB) mode controlled by the zonal advective feedback (Neelin and Jin 1993). Because the stability of the POB is sensitive to the basic state (see Kang et al. 2004 for details), it is difficult to characterize in the observations. In relatively cold mean conditions, the fast mode leads to

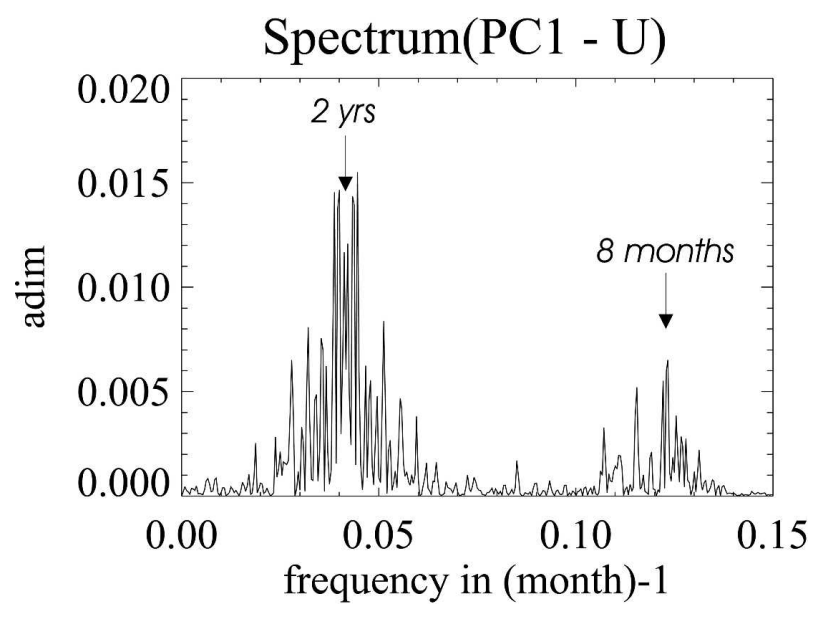

FIG. 1. Spectrum of the time series for zonal current associated with the SVD mode 1 between surface zonal current anomalies and wind stress anomalies for ARPA. The spectrum was adimensionalized by the energy integrated over the whole frequency domain. The percentage of explained variance of the mode is $26 \%$.

nearly annual La Niña events (such as in the past few years), whereas when the background in the equatorial central to eastern Pacific is warm (such as in the early 1990s) this fast mode variability may surface as minor in nearly annual El Niño events (see Jin et al. 2003). Because most CGCMs tend to produce a colder state than observed, it is expected that such a mode is enhanced in these model simulations and that, through air-sea feedbacks and nonlinearities, it interacts with the ENSO mode. The investigation of these processes could provide further insight on how to resolve the model drifts.

In this study, we investigate such processes in a global CGCM. The simulation used for this study is presented in Cibot et al. (2005, hereafter CMTD) in which the focus is on the sources of the decadal variability and its relationship with the ENSO modulation. In the present paper, we would rather concentrate on the interannual time scales and near-annual variability. Figure 1 displays the spectrum of the time series for zonal current associated to the first singular value decomposition (SVD) mode between the zonal current and wind stress full anomalies. Two main frequency bands emerge: one centered around the 2-yr period that represent the ENSO mode and the other one centered around the 8-month period that corresponds to the model fast near-annual mode. The main questions addressed in this paper are as follows: Do these two modes interact? What are the processes involved? Does the mean state relate to the characteristics of the interactions?

To investigate these questions and as a support for the interpretation, we will use an anomaly intermediate coupled model similar to Dewitte (2000, hereafter D00) prescribing the background mean state and parameters 
to the ones derived from the CGCM simulation. The paper is organized as follow. Section 2 is devoted to the description of the coupled models used in this paper. Section 3 provides a description of the CGCM vertical structure variability in order to infer the privileged time scales of variability allowed by the equatorial wave dynamics. In section 4, the characteristics of the CGCM climatology is presented and used in the intermediate coupled model for sensitivity tests. Section 5 describes the model near-annual variability and examines the coupled mechanisms associated to this fast basin mode in the light of the POB mode theory and results of the intermediate coupled experiments. Interaction between time scales is analyzed focusing on the asymmetry of the advection terms and SST. Section 6 is a discussion followed by concluding remarks.

\section{Coupled models and data descriptions}

\section{a. ARPEGE-OPA (hereafter ARPA)}

The ocean component ORCA2 is the global configuration of the Océan Parallélisé (OPA) 8 ocean general circulation model (OGCM), an hydrostatic primitive equation model with a free surface formulation (Roullet and Madec 2000). The model includes a sea ice component, the Hibler-type dynamic-thermodynamic Louvain-La-Neuve (LLN) sea ice model, developed at the Université Catholique de Louvain (UCL) by Fichefet and Morales Maqueda (1997). The atmospheric component is the third version of the Action de Recherche Petite Echelle Grande Echelle (ARPEGE) climate atmospheric general circulation model (AGCM) developed at Météo-France (Déqué et al. 1994). The standard configuration of the climate version employs a T63 triangular horizontal truncation.

The ARPEGE and ORCA-Louvain Ice Model (ORCALIM) models are coupled through the (Ocean Atmosphere Sea Ice Soil) OASIS-2.5 coupler developed at Centre Européen de Recherche et de Formation Avancée en Calcul Scientifique (CERFACS; Terray et al. 1995), which ensures the time synchronization between the GCMs and does the spatial interpolation from one grid to another.

The atmospheric initial state is in January of an uncoupled integration of ARPEGE. The initial ocean state is taken from Levitus (Antonov et al. 1998) for temperature and salinity, and is zero for the velocity field. The initial sea ice state is also from Levitus.

From this initial state, the coupled model is integrated for a spinup of $60 \mathrm{yr}$ described in CMTD. At the end of this spinup, the system has reached a quasiequilibrium state in the upper layers of the ocean. We then integrate the coupled model for $200 \mathrm{yr}$. We only consider the latest 200-yr period for the subsequent analyses. 1900 is chosen as an arbitrary initial date of this 200-yr record. More details on the model configuration and variability can be found in CMTD. This simulation will be referred as ARPA in the rest of the paper.

\section{b. $L O D C A$}

LODCA is a tropical Pacific ocean-atmosphere model of intermediate complexity. It is an extension of the Zebiak and Cane (1987)'s model in that it is based on similar physics (i.e., shallow water for both components). The ocean component comprehends three baroclinic modes with characteristics of phase speed $c_{n}$, projection coefficient $P_{n}$ and "thermocline coefficient" $\mathrm{scl}_{n}$ (used to derive the thermocline fluctuations in a multimode context and that depends directly on $N^{2}$ and the vertical derivative of the baroclinic mode vertical structures; see D00 for details) derived from Levitus. A mixed layer model is embedded in the ocean model that consists in a thermodynamical budget in a 50-m-thick surface layer. The surface heat flux is parameterized as being negatively proportional to local SST anomalies. Subsurface entrainment temperature into the surface mixed layer is parameterized as a function of thermocline depth anomalies and mean thermocline depth (cf. Dewitte and Périgaud 1996). The atmospheric component is similar to Gill (1980). The reader is invited to refer to D00 for more details about the model. We will use this model as a tool for interpreting the ARPA variability, prescribing parameters and mean climatological states derived from ARPA and/or observations.

\section{Interannual variability and vertical mode characteristics}

The time scale of the interannual variability in the tropical Pacific is critically dependent on the background mean state (e.g., An and Jin 2000; Federov and Philander 2001; Wang and An 2001), itself constrained by the thermocline vertical structure. The latter determines the "memory" of the tropical Pacific system. The high-order baroclinic modes of the equatorial Pacific with a slower wave speed than the gravest mode tend to impose the slower mode of variability whereas the first baroclinic mode is associated to a relatively fast variability adjustment (D00; Yeh et al. 2001)

As a preliminary diagnostic of the ARPA variability, we wish to estimate the energy distribution on the baroclinic modes in order to infer how the equatorial wave dynamics impact the SST variability in the model. Note that this information will be also used later for tuning the Intermediate Coupled Model (ICM) and carring out sensitivity experiments. 

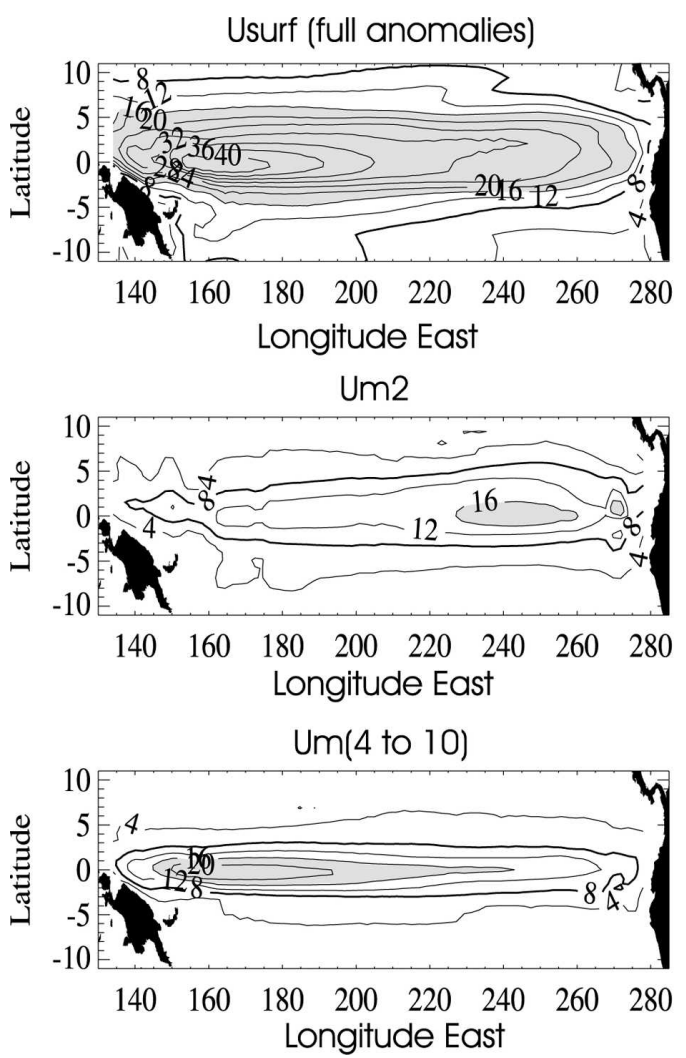

Figure 2 represents the projection of the simulated zonal current anomalies onto the vertical mode structure of the baroclinic modes. The vertical modes were calculated in a similar way than in Dewitte et al. (1999). The reader is invited to refer to this work for more technical details about the method. Inspection of Fig. 2 first indicates a zone of large variability in the far western Pacific for the total surface current anomaly (Fig. 2a), the summed-up contribution of mode 4-10 (Fig. 2e) that accounts for the Ekman component of the variability, and the first baroclinic mode contribution (Fig. $2 b$ ). It is suggestive of a dominant forcing of Rossby waves considering the large variability of zonal wind stress in the far off-equatorial western Pacific (see CMTD). This is significantly different from results of the same OGCM forced with realistic winds and heat flux (Dewitte et al. 1999) or assimilation products (Moon et al. 2004). In the latter, the variability of the winds and associated zonal currents is located more in the equatorial central Pacific. Also in contrast with the forced OGCM results, the strength of the baroclinic mode 3 in ARPA is almost as energetic as mode 2 in the eastern Pacific.

To confirm the fact that the wave dynamics in ARPA is associated with higher baroclinic modes than in observations, classical parameters of a shallow-water
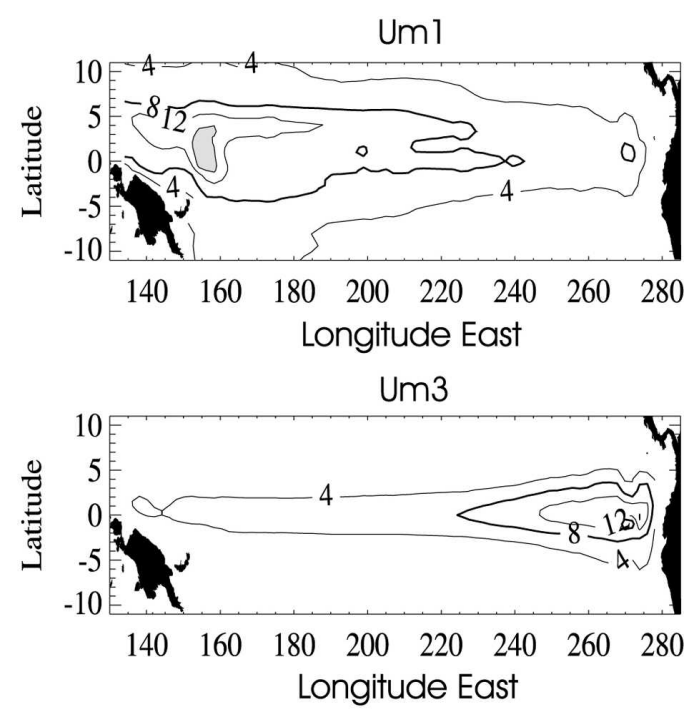

FIG. 2. Maps of variability (rms) of (a) the ARPA surface currents estimated as the average of the top four model levels, the contributions (b) of the first baroclinic mode, (c) of the second baroclinic mode, (d) of the third mode, and (e) of the sum of contributions of the fourth to the tenth mode $\left[\mathrm{cm} \mathrm{s}^{-1}\right.$ and contour interval $(\mathrm{CI})=4 \mathrm{~cm} \mathrm{~s}^{-1}$ ]. Shading is for values above $16 \mathrm{~cm}^{-1}$.

ocean model are calculated: 1) the projection coefficient of the wind, $\left.P_{n} ; 2\right)$ the thermocline coefficient, $\operatorname{scl}_{n}(z)$ introduced in D00 and used to derive the thermocline fluctuations from the baroclinic mode contributions to pressure anomalies; and 3) the phase speed associated with the baroclinic modes, $c_{n}$. The value of the first two coefficients, $\left(P_{n}, \mathrm{scl}_{n}\right)$, can have a large impact on simple coupled model variability as shown in D00, Yeh et al. (2001), and Moon et al. (2004). The sensitivity to values of $\mathrm{c}_{n}$ is much weaker within a range of variation of $20 \%-30 \%$. For this reason, we will not pay too much attention to $c_{n}$ in this study considering that values derived from ARPA are close to the ones derived from Levitus along the equator (difference less than $15 \%$ for the first three baroclinic modes). The peak variability for wind stress being in the central Pacific, the values for thermocline coefficient, $\mathrm{scl}_{n}$, and projection coefficient, $P_{n}$, are given in Table 1 at $180^{\circ}$ for the first three baroclinic modes, along with the values used in D00. Longitudinal variability is comparable to what could be obtained from an OGCM simulation forced with realistic winds (Dewitte et al. 1999) with a dominant first (second) baroclinic mode in the western (eastern) Pacific that decreases eastward (westward) (not shown). In the far eastern Pacific, the value of $P_{n}$ for a mode order higher than 3 is large consistently with 
TABLE 1 . The baroclinic mode parameters for the first three baroclinic modes at $180^{\circ}$ as derived from ARPA and as in D00: $P_{n}$ and $\mathrm{scl}_{n}$ are adimensionalized by $150 \mathrm{~m}$ and $\left(c_{n}^{2} / g .150\right)$, respectively. The $c_{n}$ is in $\mathrm{m} \mathrm{s}^{-1}$.

\begin{tabular}{cccccccc}
\hline \hline \multirow{2}{*}{$\begin{array}{c}\text { Baroclinic } \\
\text { mode order }\end{array}$} & \multicolumn{3}{c}{ ARPA } & & \multicolumn{3}{c}{$\mathrm{D} 00$} \\
\cline { 2 - 4 } \cline { 6 - 8 } & $P_{n}$ & $\mathrm{scl}_{n}$ & $c_{n}\left(\mathrm{~m} \mathrm{~s}^{-1}\right)$ & & $P_{n}$ & $\mathrm{scl}_{n}$ & $c_{n}\left(\mathrm{~m} \mathrm{~s}^{-1}\right)$ \\
\hline$n=1$ & 0.55 & 0.85 & 2.87 & & 0.60 & 0.70 & 2.70 \\
$n=2$ & 0.55 & 0.77 & 1.73 & & 0.60 & 0.60 & 1.60 \\
$n=3$ & 0.23 & 0.53 & 1.01 & & 0.10 & 0.55 & 1.10 \\
\hline
\end{tabular}

a shallower thermocline in this region. In the central Pacific, $P_{1}$ equals $P_{2}$ similar to what is used in D00. However, the $P_{3}$ in ARPA is $150 \%$ larger than in D00. The large value of $\mathrm{P}_{3}$ should favor the low periods of variability in a shallow-water coupled system similar to the one used in this study.

At $180^{\circ}$, the mean thermocline depth is $128 \mathrm{~m}$. This is the depth where the $\mathrm{scl}_{n}$ are used for deriving the thermocline displacements associated to wave dynamics. Value of $\mathrm{scl}_{n}$ at $128 \mathrm{~m}$ are rather realistic, comparable to what is obtained from Levitus data for instance, although slightly larger for modes 1 and 2 . Note, however, that a thermocline depth in the western Pacific is shallower in ARPA $(\sim 128 \mathrm{~m})$ than in the observation ( $\sim 170 \mathrm{~m}$; see the next section).

To summarize, high-order baroclinic contributions in ARPA are significantly larger than in the real world as suggested by modeling studies using OGCM forced with realistic winds and heat flux (Dewitte et al. 1999) or assimilation products (Moon et al. 2004). According to D00 or Yeh et al. (2001), with such values for the $P_{n}$, the time scale of the variability should be in the 3-5-yr period range, the higher baroclinic modes favoring the Kelvin type, which is an unstable mode (Hirst 1986) that propagates slowly eastward. As a consistency check with this latter statement, the LODCA model is run using the mean $\left(P_{n}, \mathrm{scl}_{n}, c_{n}\right)$ parameters derived from ARPA, everything else being the same as in D00.
This experiment is called Exp0 (see Table 2 for the experiments settings and characteristics). Results are displayed in Fig. 3 for the Niño-3 SST index. LODCA "tuned" from the ARPA outputs exhibits quasi-regular oscillations at a $\sim 4.9$-yr period larger than D00. Assuming that the time scale of the interannual variability is controlled by the ocean wave dynamics, results of Exp0 suggest that the quasi-biennial ENSO mode simulated by ARPA is due to some other model peculiarities than its baroclinic mean structure, possibly its mean state and seasonal cycle.

\section{Impact of the climatology on the model variability}

In this section, we first describe the characteristics of the climatological fields simulated by ARPA and then use LODCA relative to different climatologies in order to examine why ARPA simulates a quasi-biennial mode for ENSO.

\section{a. Climatology simulated in ARPA}

As shown in CMTD, there is a cold bias in the western equatorial Pacific resulting from a cold bias in the regions of ITCZ and the South Pacific convergence zone (SPCZ; by $1^{\circ}-2^{\circ} \mathrm{C}$ ) due to stronger off-equatorial branches of the trade winds. This in particular also contributes to the too weak mean SST zonal gradient along the equator in the central Pacific as compared to the observations. At $160^{\circ} \mathrm{W}$, it is twice as low as for the observations, which leads to weaker equatorial trade winds than observed (see Fig. 4, bottom). The associated thermocline slopes and the ones derived from forced simulations with LODCA are also plotted in Fig. 4, which shows that 1) the thermocline is shallower in ARPA than in the observations in the central and western Pacific and 2) the mean equatorial trade winds do constrain its longitudinal structure

TABLE 2. Experiments with LODCA.

\begin{tabular}{|c|c|c|c|c|c|c|}
\hline & $\left(P_{n}, c_{n}, \mathrm{scl}_{n}\right)$ & $(u, v, w)$ Climatology & SST climatology & $(\partial \bar{T} / \partial z)$ & Forcing & $\begin{array}{l}\text { ENSO dominant } \\
\text { frequency }(T)\end{array}$ \\
\hline D00 & Levitus & Obs & Obs & Obs & Coupled & $3.6 \mathrm{yr}$ \\
\hline Exp0 & $\operatorname{ARPA}\left(c_{D}=1.8\right)$ & Obs & Obs & Obs & Coupled & $4.9 \mathrm{yr}$ \\
\hline Exp1 & $\operatorname{ARPA}\left(c_{D}=2.3\right)$ & ARPA & ARPA & ARPA & $\begin{array}{l}\text { ARPA wind } \\
\text { stress anomalies }\end{array}$ & $2.5 \mathrm{yr}$ \\
\hline Exp2 & $\operatorname{ARPA}\left(c_{D}=2.3\right)$ & ARPA & ARPA & ARPA & Coupled & $2.5 \mathrm{yr}$ \\
\hline Exp2.mean & $\operatorname{ARPA}\left(c_{D}=2.3\right)$ & $\begin{array}{l}\text { ARPA - annual } \\
\text { mean }\end{array}$ & $\begin{array}{l}\text { ARPA - annual } \\
\text { mean }\end{array}$ & ARPA & Coupled & $2.6 \mathrm{yr}$ \\
\hline Exp0-Warpa & $\operatorname{ARPA}\left(c_{D}=1.8\right)$ & $\begin{array}{l}\text { Obs for }(u, v) \\
\text { ARPA for } w\end{array}$ & Obs & Obs & Coupled & $2.9 \mathrm{yr}$ \\
\hline Exp0-HCarpa & $\operatorname{ARPA}\left(c_{D}=1.8\right)$ & $\begin{array}{l}\text { ARPA for }(u, v) \\
\text { Obs for } w\end{array}$ & Obs & Obs & Coupled & $1 \mathrm{yr}$ \\
\hline
\end{tabular}




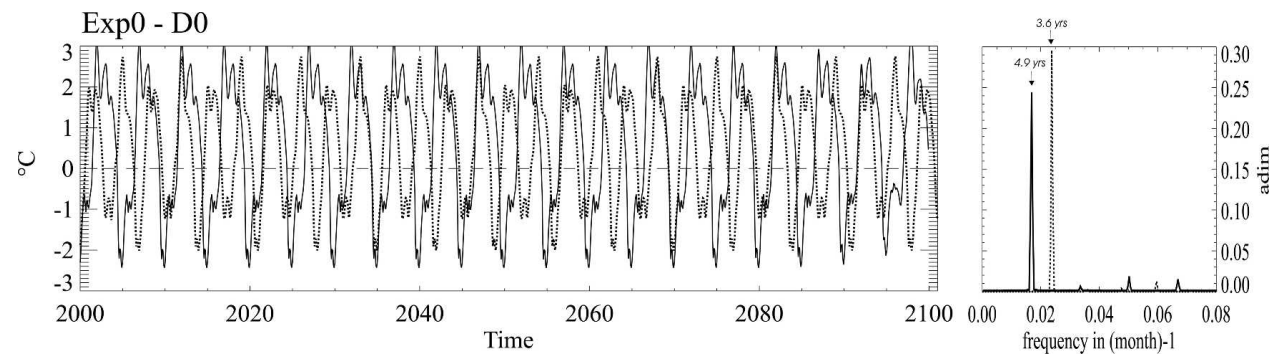

FIG. 3. (a) Niño-3 SST for (full line) LODCA tuned with the ARPA $\left(P_{n}, \mathrm{scl}_{n}, c_{n}\right)$ parameters and for (dotted line) LODCA configured as in D00. A total of $100 \mathrm{yr}$ are displayed $\left({ }^{\circ} \mathrm{C}\right)$. (b) The associated Niño-3 SST frequency spectrum for the entire period (200 yr) and adimensionalized by the energy integrated over the whole frequency domain.

since the ARPA mean thermocline (approximated by the $20^{\circ} \mathrm{C}$ isotherm) agrees well with the linear model simulation.

These characteristics of the year mean and seasonal wind stress imprint biases to the equatorial surface circulation. To visualize the differences in climatological cycle for horizontal currents and upwelling, the oceanic component of LODCA calibrated with the $\left(P_{n}, \mathrm{scl}_{n}, c_{n}\right)$ parameters derived from ARPA is forced with the ARPA climatological wind stress calculated over 200 yr. Results are compared to the standard climatology of LODCA [obtained from Florida State University (FSU) wind stress]. This method allows us to get a direct estimate of climatological upwelling from ARPA, which remains difficult to obtain for the direct modeled vertical velocities that are comparable to estimate from a different wind product. This estimate of climatological velocity circulation will be also used later for the simple coupled model experiments.

Figure 5 presents the results for zonal current. An estimate of the seasonal surface zonal current obtained from the average of the top four model (ARPA) levels is also presented (Fig. 5c). Interestingly, the LODCA model is able to reproduce most of the characteristics of the ARPA seasonal cycle, with large currents to the west from March to May in the western Pacific, and a relatively weak westward (eastward) current of the order of $\sim 30-40(\sim 10) \mathrm{cm} \mathrm{s}^{-1}$ in the eastern (western) Pacific around October. However, a direct estimate from ARPA outputs presents less westward-propagating features than the LODCA estimate and no westward currents in the central Pacific as compared to the LODCA estimate from the ARPA seasonal wind stress. As an indication of the realism of these currents, the estimate from the LODCA model forced with the FSU seasonal wind stress is presented. The most striking discrepancy is for the westward currents that are overestimated (underestimated) in the west (east) by ARPA by a factor of $\sim 2$. Comparison with in situ mea- surements can be found in appendix A of D00. This has to be related to the climatological mean wind forcing, which is too strong in the off-equatorial region and too weak along the equator. This, in particular, leads to an equatorial upwelling that is too weak in the eastern Pacific as confirmed by the estimate of vertical velocity from LODCA forced with the ARPA climatological wind stress (see Fig. 6). The LODCA model exhibits an

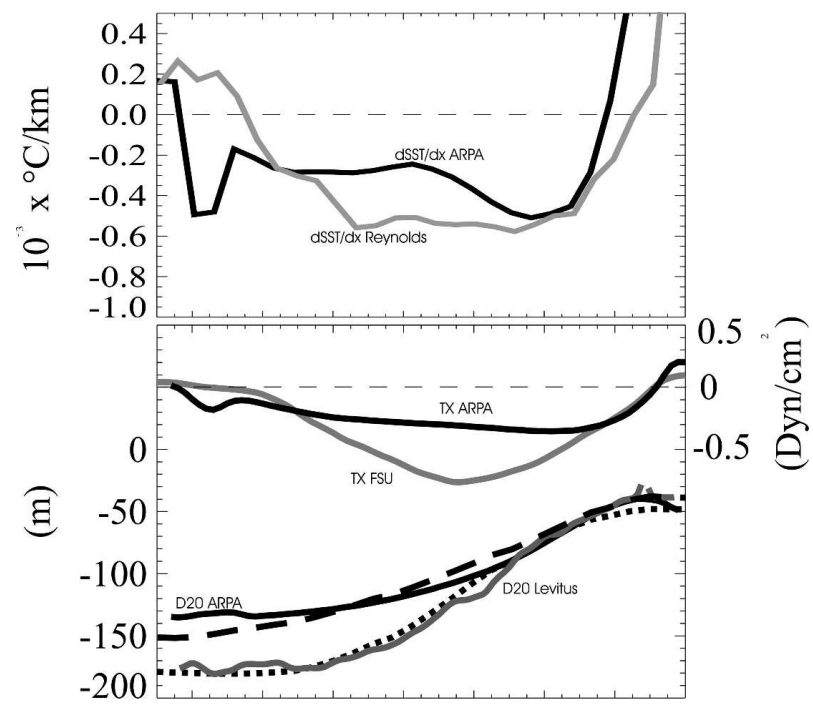

140160180200220240260280 Longitude East

FIG. 4. Year-mean climatology of (a) SST zonal gradient, (b) zonal wind stress and thermocline depths as a function of longitude along the equator for (black full lines) ARPA and (gray full lines) the observations $\left(10^{-3}{ }^{\circ} \mathrm{C} \mathrm{km}^{-1}\right.$ for SST zonal gradient, dyn $\mathrm{cm}^{-2}$ for zonal wind stress, and $\mathrm{m}$ for thermocline depth). Observations are from Reynolds for SST, Levitus for thermocline depth, and FSU for zonal wind stress. Results of LODCA forced with climatological wind stress as derived from ARPA and observations (FSU) are plotted in black dashed and dotted lines, respectively, for the mean thermocline depth. For both simulations, parameters for LODCA $\left(P_{n}, \mathrm{scl}_{n}, c_{n}\right)$ are derived from ARPA and observations, respectively. 


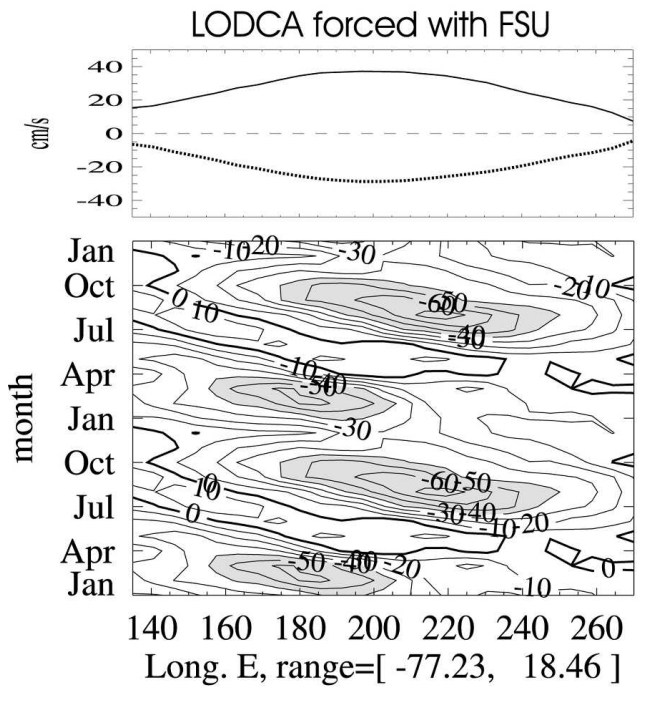

a)

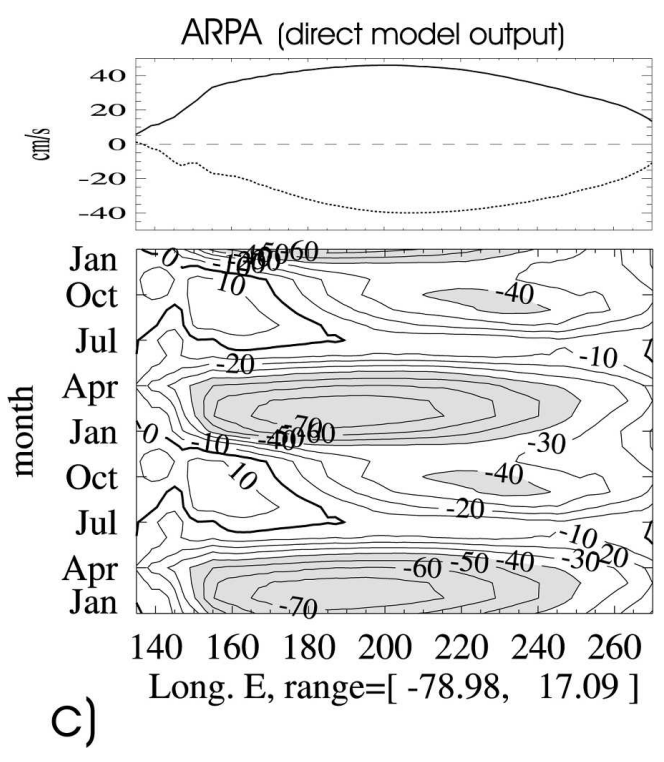

upwelling rate that is more reduced (factor of $\sim 2$ ) when compared to the estimate forced with FSU winds.

\section{b. Experiments with LODCA}

The ability of the LODCA intermediate model to reproduce the ARPA SST anomalies is first examined in a forced mode (i.e., when LODCA is forced with the ARPA wind stress anomalies). This experiment is called Exp1 (see Table 2 for experiment description). In LODCA standard experiments (D00), the climatology corresponds to the one originally derived from observations and simulations forced by FSU winds. Here, we prescribe the climatologies for currents and SST to the ones simulated by the ARPA climatological wind stress. The mean temperature vertical gradient between

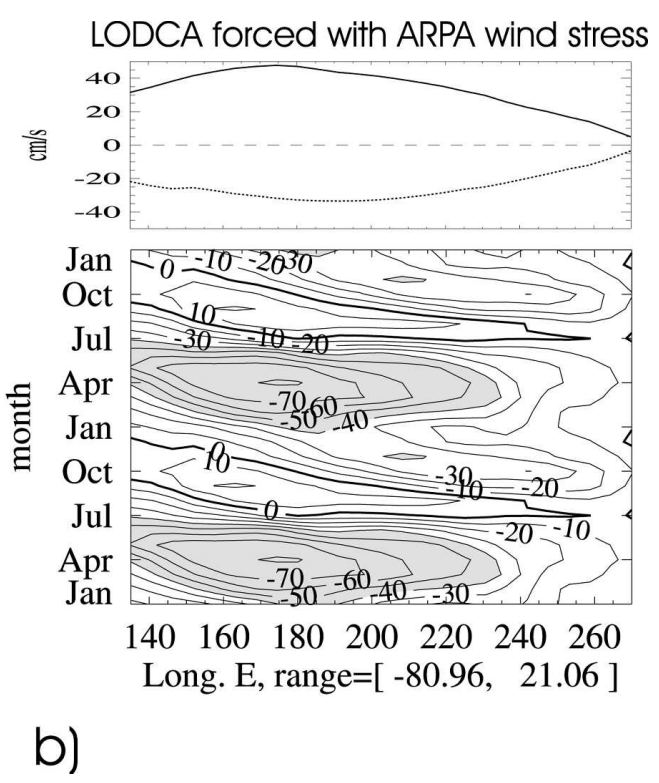

FIG. 5. Time-longitude plots of equatorial climatological zonal currents for (a), (b) LODCA forced with FSU or ARPA wind climatologies, and for (c) the average of the four uppermost levels of ARPA. The model parameters $\left(P_{n}, c_{n}, \mathrm{scl}_{n}\right)$ are derived from (a) Levitus and from (b) ARPA $\left(\mathrm{s}^{-1}, \mathrm{CI}=10 \mathrm{~cm} \mathrm{~s}^{-1}\right)$. The shaded zone corresponds to westward currents. Rms (full line) and mean (dotted line) values in time are plotted as a function of longitude on top of each diagram.

the surface and the base of the mixed layer $(50 \mathrm{~m})$, $(\partial \bar{T} / \partial z)$, is also prescribed to the one estimated from ARPA, but this gradient does not differ much from the observed climatology prescribed in LODCA standard experiments (D00) and it was checked that the coupled LODCA experiments further carried out in this study do not show significant sensitivity to the $(\partial \bar{T} / \partial z)$ we prescribe. LODCA is more sensitive to the coefficients of thermal dissipation and drag. To match the amplitude of the SST anomalies simulated by ARPA and LODCA Exp1, we increase the "standard" values in LODCA (D00) by $25 \%$ for the drag coefficient and from 100 to 115 days for the thermal dissipation $(-\alpha T)$. The Niño-3 SST index thus simulated by LODCA Exp1 is presented in Fig. $7 \mathrm{~b}$ and can be compared to the 

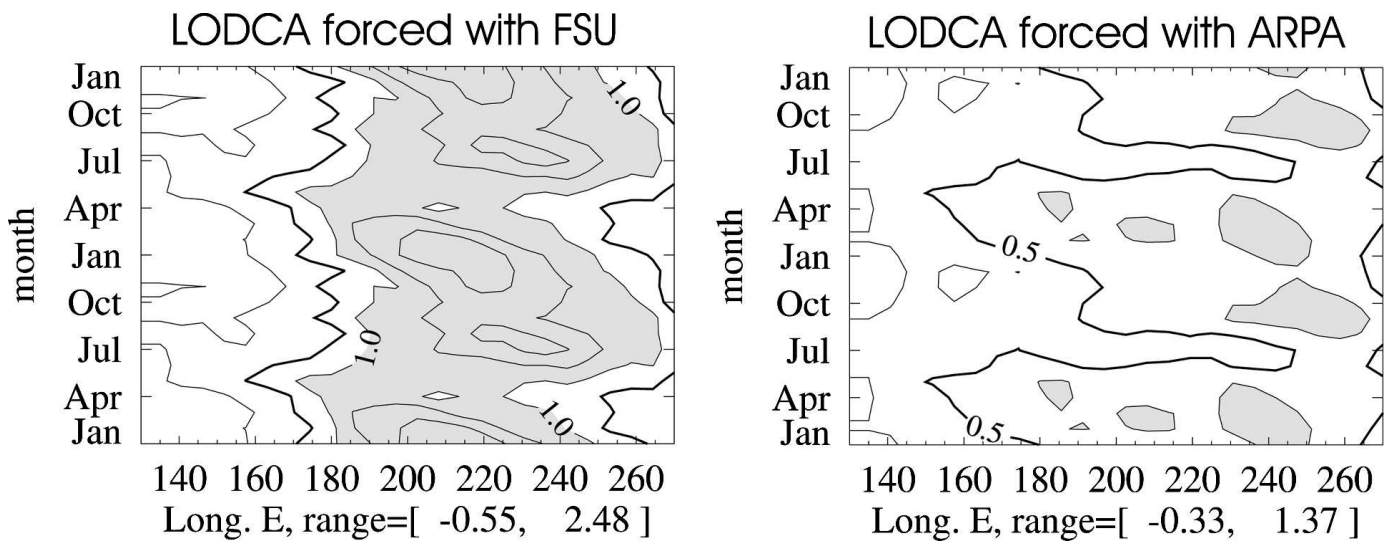

FIG. 6. Time-longitude plots of equatorial climatological vertical velocity for LODCA forced with (a) FSU winds and the (b) ARPA seasonal winds $\left(\mathrm{m} \mathrm{day}^{-1}, \mathrm{CI}=0.5 \mathrm{~m}_{\text {day }}{ }^{-1}\right.$ ). The shading is for velocity lower than $1.0 \mathrm{~m}_{\text {day }}{ }^{-1}$.

equivalent ARPA indices (Fig. 8a). Exp1 simulates El Niño events and ENSO modulation [quantified by the interannual (2-7 yr) wavelet variance of the Niño-3 SST (N3VAR) index] in good agreement with ARPA. The two model Niño-3 SST indices are correlated by 0.87 with a root-mean-square (rms) difference equal to $0.69^{\circ} \mathrm{C}$ only. The two model N3VAR indices are correlated by 0.90 , the variance of the N3VAR index is $0.48^{\circ} \mathrm{C}^{2}$ for ARPA, $0.35^{\circ} \mathrm{C}^{2}$ for Exp1, and their difference is $0.22^{\circ} \mathrm{C}^{2}$.

As long as LODCA is forced by the ARPA wind stress anomalies, we find similar levels of agreement regardless of the climatology prescribed in LODCA; with the D00 standard climatologies and parameters, the correlation between LODCA and ARPA is 0.90 and 0.95 for the Niño-3 SST and N3VAR indices, respectively. Prescribing the ARPA climatology slightly affects the amplitude only, the Niño-3 SST and the N3VAR index variability being decreased by $1 \%$ and increased by $3 \%$, respectively. The role of the prescribed climatology in LODCA is negligible in Exp1 where the ocean is forced by ARPA winds, but when air-sea feedbacks are explicitly taken into account in LODCA (coupled mode), the sensitivity of the model to the prescribed climatology is modified as shown below.

The LODCA model is integrated in a coupled experiment (Exp2) like D00, except that the ARPA climatologies and the parameters are the ones defined in Exp1. Results for Exp2, presented in Fig. 8c, show oscillations at a period significantly shorter than for LODCA Exp0 (Fig. 3) and a broader spectrum. Exp2 simulates an irregular ENSO cycle, the (rms) variability of the N3VAR index reaches $0.15^{\circ} \mathrm{C}$ instead of 0.08 for Exp0. The most striking result is that by contrast to D00 and Exp0 that simulate an ENSO period longer than 3 $\mathrm{yr}$ (3.6 and $4.9 \mathrm{yr}$, respectively), Exp2 fluctuates at a quasi-biennial period like ARPA. These results demonstrate that the climatological background is indeed responsible for the energetic quasi-biennial oscillations simulated by ARPA.

To differentiate the role of the year mean climatology versus the seasonal cycle, and as a sensitivity experiment, LODCA is also run with the year mean values for $(u, v, w)$ and SST instead of the monthly varying climatologies (everything else being as in Exp2). This experiment, called Exp2.mean, simulates time series of the Niño-3 SST (Fig. 7d), which also oscillates at a quasi-biennial period (see Table 2). Compared to Exp2, the oscillations in Exp2.mean are much more regular and the N3VAR variability has a smaller amplitude (see Table 2), suggesting that the seasonal cycle participates to destabilizing the ENSO mode and to widening the spectrum of simulated variability. In section 5 of this paper, we come back on the issue of how seasonal and near-annual changes participate to the structure of the model mean state and interact with the interannualto-decadal changes.

To summarize this section, the results of these experiments demonstrate that, although the ARPA thermocline vertical structure favors the slow time scales, biases in the climatological mean of SST, horizontal surface circulation, and/or upwelling are associated to the fast ENSO mode in the model. Through advection, the climatologies modify the coupled variability toward more energy in the high frequencies. Interestingly, the interaction between near-annual variability and ENSO mode is also altered as illustrated by the Fig. 8, which is equivalent to Fig. 1 for Exp0 and Exp2. In Exp2, the ratio of the high-frequency band centered around the 8-month period and the one centered around the dominant ENSO period is increased compared to Exp0. This shows up even more on the second principal component of Exp2 for the zonal current, which exhibits 

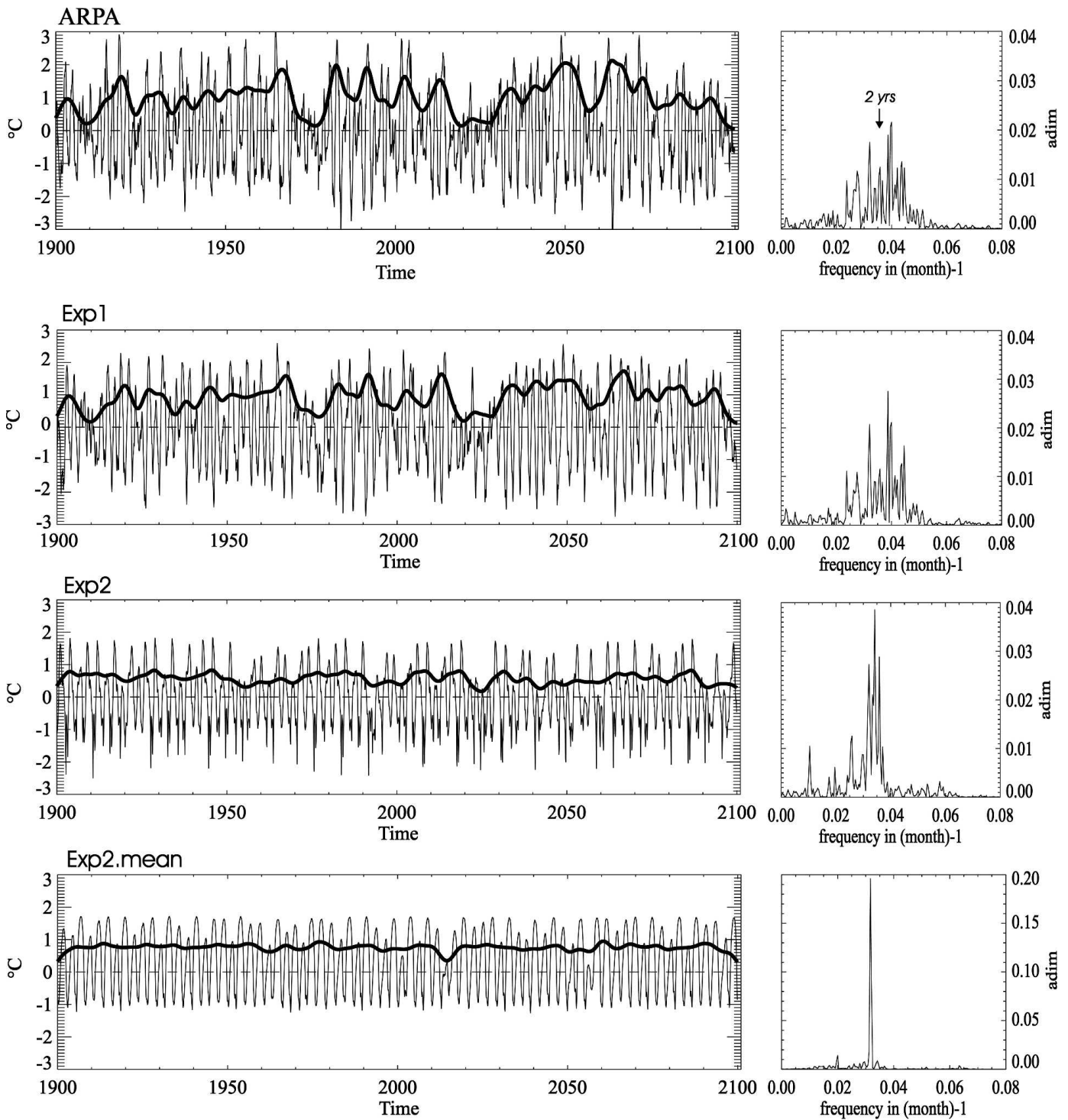

FIG. 7. (thin full line) Niño-3 SST and (thick line) N3VAR indices for (a) ARPA; (b) LODCA forced with the zonal and meridional wind stress anomalies derived from ARPA (Exp1); (c), (d) for LODCA run in a coupled mode (Exp2) with prescribed seasonally varying climatologies (Exp2) and year mean climatologies (Exp2.mean) derived from ARPA. The N3VAR index is defined by the interannual (2-7 yr) wavelet variance of the Niño-3 SST index. All three LODCA experiments have the ARPA climatologies and $\left(P_{n}, \mathrm{scl}_{n}, c_{n}\right)$ parameters $\left({ }^{\circ} \mathrm{C}\right.$ for Niño-3 SST, ${ }^{\circ} \mathrm{C}^{2}$ for N3VAR). (right) The associated Niño-3 SST frequency spectrum adimensionalized by the energy integrated over the whole frequency domain.

two prominent peaks at $2.5 \mathrm{yr}$ and 8 months in its spectrum. It also explains more variance in Exp2 than in Exp0 (18\% in Exp2 versus 7\% in Exp0).

\section{Impact of the near-annual mode and time-scale interactions}

The following section is devoted to the description of the fast near-annual mode in ARPA and to the study of the nature and dynamics of the interaction between the ENSO, the mean state, and the near-annual time scales.

\section{a. Near-annual mode characteristics in ARPA}

Following Kang et al. (2004), we apply a high-pass filter with a cutoff period at 12 months on the ARPA outputs. An SVD is then performed on the filtered SST and wind stress anomalies. The two dominant modes of this decomposition are both clearly associated to the 8 -month period and explain $38 \%$ and $20 \%$ of covariance, respectively (not shown). Results are rather presented for the SVD between wind stress and zonal current anomalies for which the first mode by itself ex- 

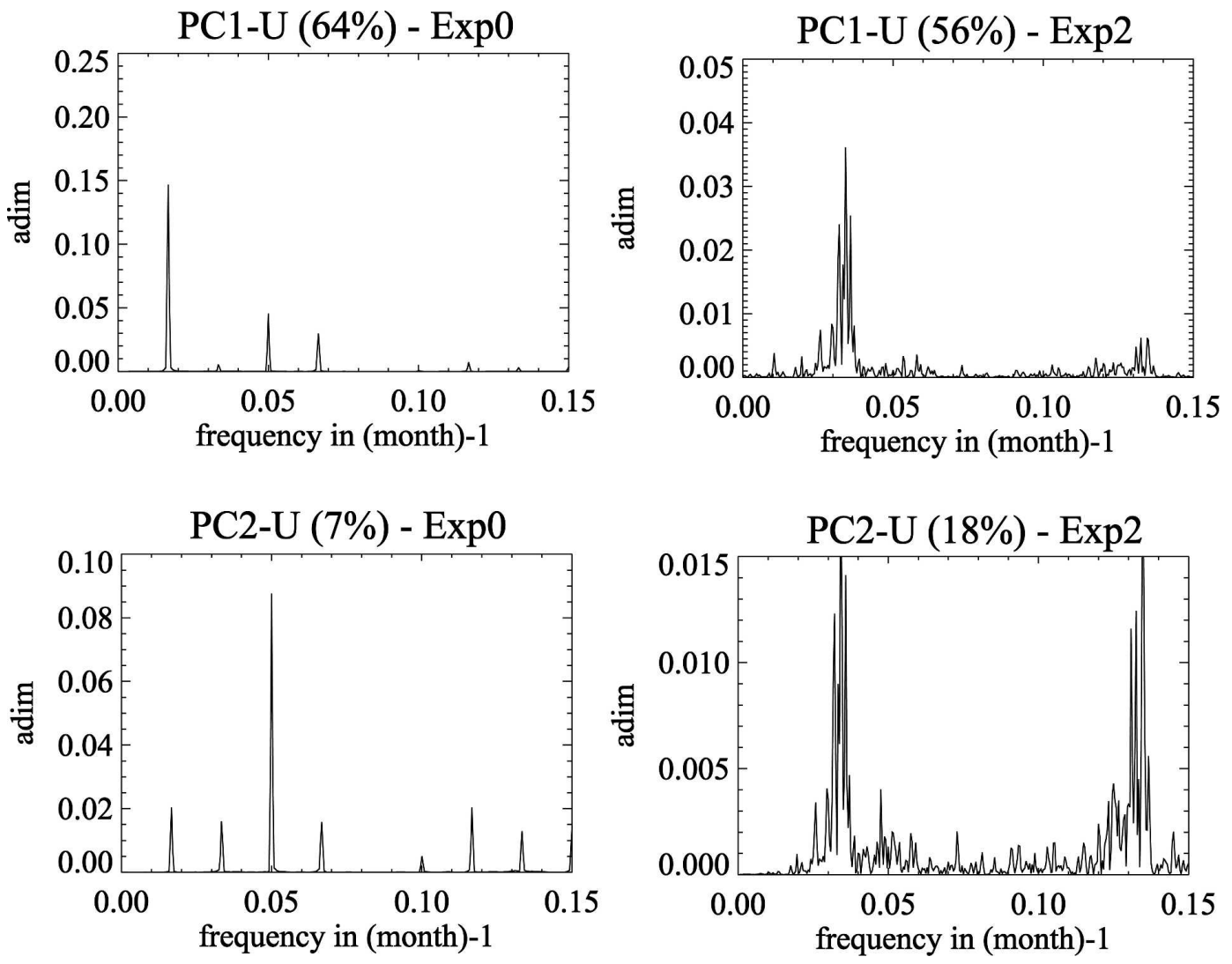

FIG. 8. Spectrum of the time series for zonal current associated to the SVD mode (top) 1 and (bottom) 2 between surface zonal current anomalies and wind stress anomalies for (left) Exp0 and (right) Exp2. The spectrum was adimensionalized by the energy integrated over the whole frequency domain. The percentage of explained variance of the modes is indicated at the top of each panel.

plains as much as $83 \%$ of the covariance (Fig. 9). The associated time series are dominated by $\sim 8$-month oscillations, correlated by 0.76 . The zonal current SVD mode has a maximum variability in the western equatorial Pacific with a symmetric horseshoe pattern characteristic of Rossby waves. The SVD was also performed on the first or second baroclinic zonal current anomalies instead of the full surface current anomalies. Results give patterns for wind stress and currents that are similar to the ones presented in Figs. 9a,b, in which the explained covariances are $59 \%$ and $68 \%$ with the time series correlated by 0.73 and 0.67 for the first and second baroclinic modes, respectively. The zonal wind stress pattern is characterized by a strong signal near the equator in the far western Pacific, easterlies being associated with large westward equatorial zonal currents. By projecting zonal wind stress anomaly (TXA) mode 1 on the Kelvin and first Rossby meridional structures of the three baroclinic modes present in ARPA, it was verified that the TXA maximum at $\left(10^{\circ} \mathrm{S}, 160^{\circ} \mathrm{W}\right)$ has a negligible impact on the equatorial wave dynamics of LODCA.
To diagnose the propagating nature of this fast mode, a bivariate space-time spectral analysis (Hayashi 1977) is applied on the high-pass-filtered ARPA outputs (zonal wind stress, SST, D20, and zonal current) along the equator. Results are displayed in Fig. 10. Except for D20, this figure shows that eastward and westward propagations are found for all fields during an 8-10month period. Note that none of these propagations have the speed of free Kelvin or Rossby equatorial waves: they rather correspond to basin-wide standing oscillations. This is clearly the case for the zonal currents, which are equally distributed in eastward and westward periods at 8.5 months at the basin scale. Westward propagation is not visible for D20 since Rossby wave contribution is weak along the equator for this field.

\section{b. Near-annual mode in LODCA: Sensitivity to the climatological state}

To further understand the link between climatology and the fast near-annual modes of ARPA, Exp0 and Exp2 are analyzed as above. The 12-month high-pass- 

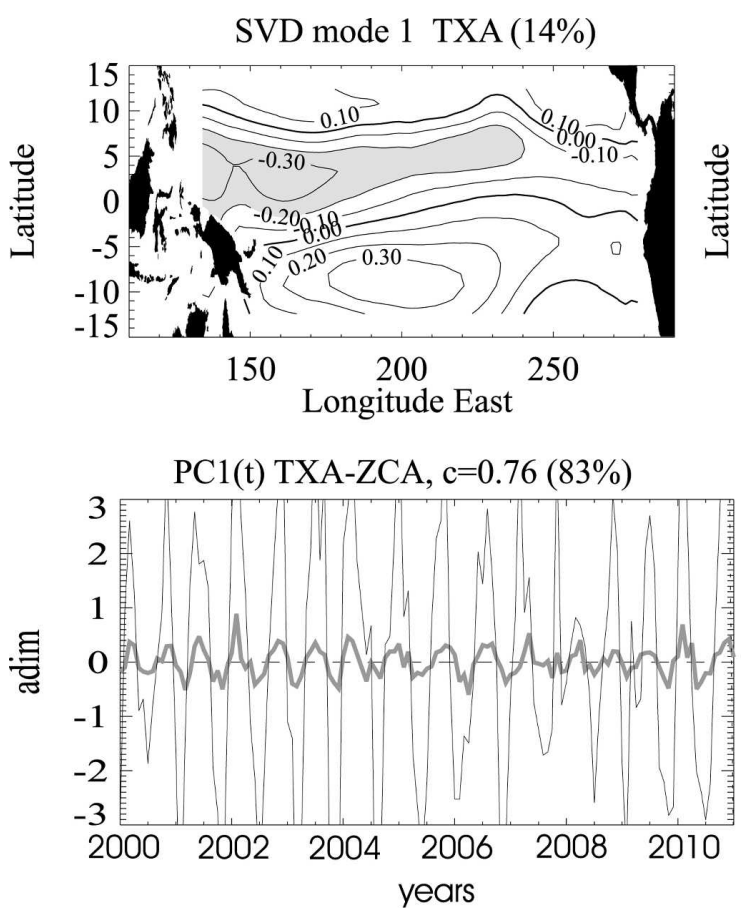

SVD mode 1 ZCA (28\%)
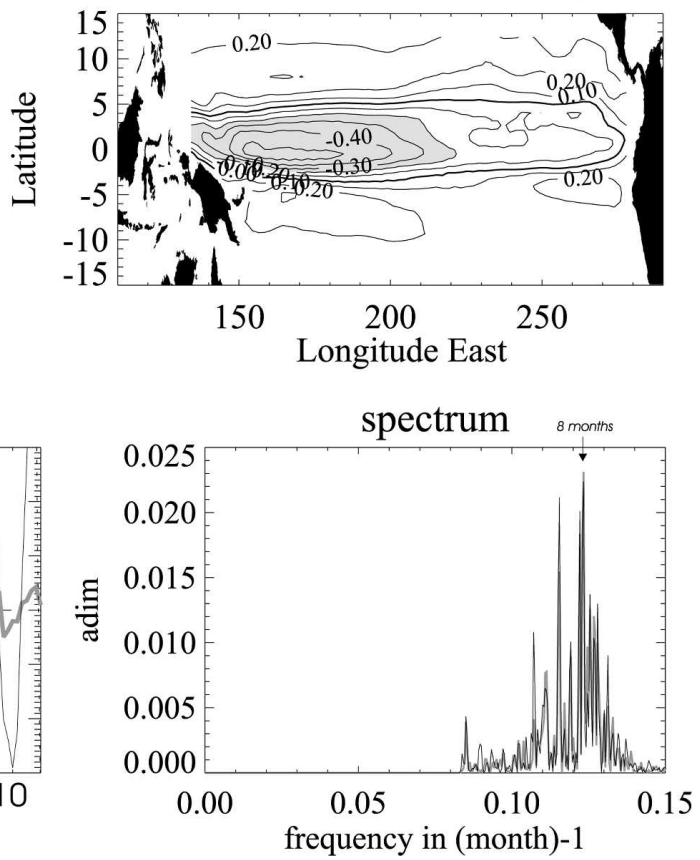

FIG. 9. First SVD mode between the 12-month high-pass-filtered wind stress and surface zonal current anomalies: spatial pattern for (a) zonal wind stress and (b) zonal current anomalies, (c) associated time series (gray thick line for zonal wind stress and thin black line for zonal current), and (d) spectrum adimensionalized by the energy integrated over the whole frequency domain. CI $=0.1$ units. Shading is for anomalies smaller than -0.2 units. Spatial patterns are normalized by their respective variance over the domain and multiplied by 10 . Units for the time series are dyn $\mathrm{cm}^{-2}$ for zonal wind stress and $\mathrm{m} \mathrm{s}^{-1}$ for zonal current. Percentage of explained variance for current and zonal wind stress is indicated above the top panels.

filtered wind stress and zonal current anomalies are decomposed in SVD, and results are presented for the two experiments (Fig. 11). First, note that zonal current anomaly patterns are similar to ARPA with a symmetric horseshoe meridional structure and a maximum of amplitude in the western equatorial Pacific. Relative to the wind, the magnitude of current anomalies is twice larger than in ARPA (cf. Figs. 9a,b), which results from equatorial wave dynamics stronger in LODCA than in ARPA. The percentage of covariance for both Exp0 and Exp2 is $64 \%$, but because the total SSTA variability in Exp0 is about 1.5 times larger than in Exp2, the near-annual mode has a role that is relatively larger in Exp2 than in Exp0. The striking difference between Exp0 and Exp2 is clearly illustrated in the energy spectra of the time series: whereas the Exp0 spectrum consists in prominent frequencies at 10, 8, and 7 months, the Exp2 spectrum is much wider, centered on frequencies close to (7.5 months $)^{-1}$ and overall resembles ARPA spectrum (Fig. 9d). The difference in characteristics of the spectrum of Exp0 and Exp2 can be explained by the difference in longitude of the center of action for the equatorial wind, itself due to the differ- ences in climatological states between the two experiments. As a matter of fact, extrema in Exp2 patterns are $\sim 15^{\circ}$ to the east of those in Exp0. Because the coupled POB mode is controlled by the zonal advective feedback, which takes place in the western Pacific, the closer the wind center is to the western boundary the longer the period of oscillations. Note that similar reasoning for the ENSO mode has led to the conclusion that it is when the wind center expands more to the east that the ENSO period is the longest (Périgaud et al. 2000; An and Wang 2000) because the ENSO mode is more controlled by a thermocline feedback that is most active in the east (Kang et al. 2004). The presence of several distinct peaks in Exp0 is due to the westernmost location of the center of action that allows for the resonance of the baroclinic modes and their asynchronous interaction through air-sea coupling. For instance, the difference in time for the traveling back and forth across the Pacific for the equatorial waves of the first and second baroclinic modes is $\sim 7$ months so that airsea coupling associated to the near-annual mode can take place every $\sim 7$ months. For Exp2, the center of action of the near-annual mode is displaced eastward, 

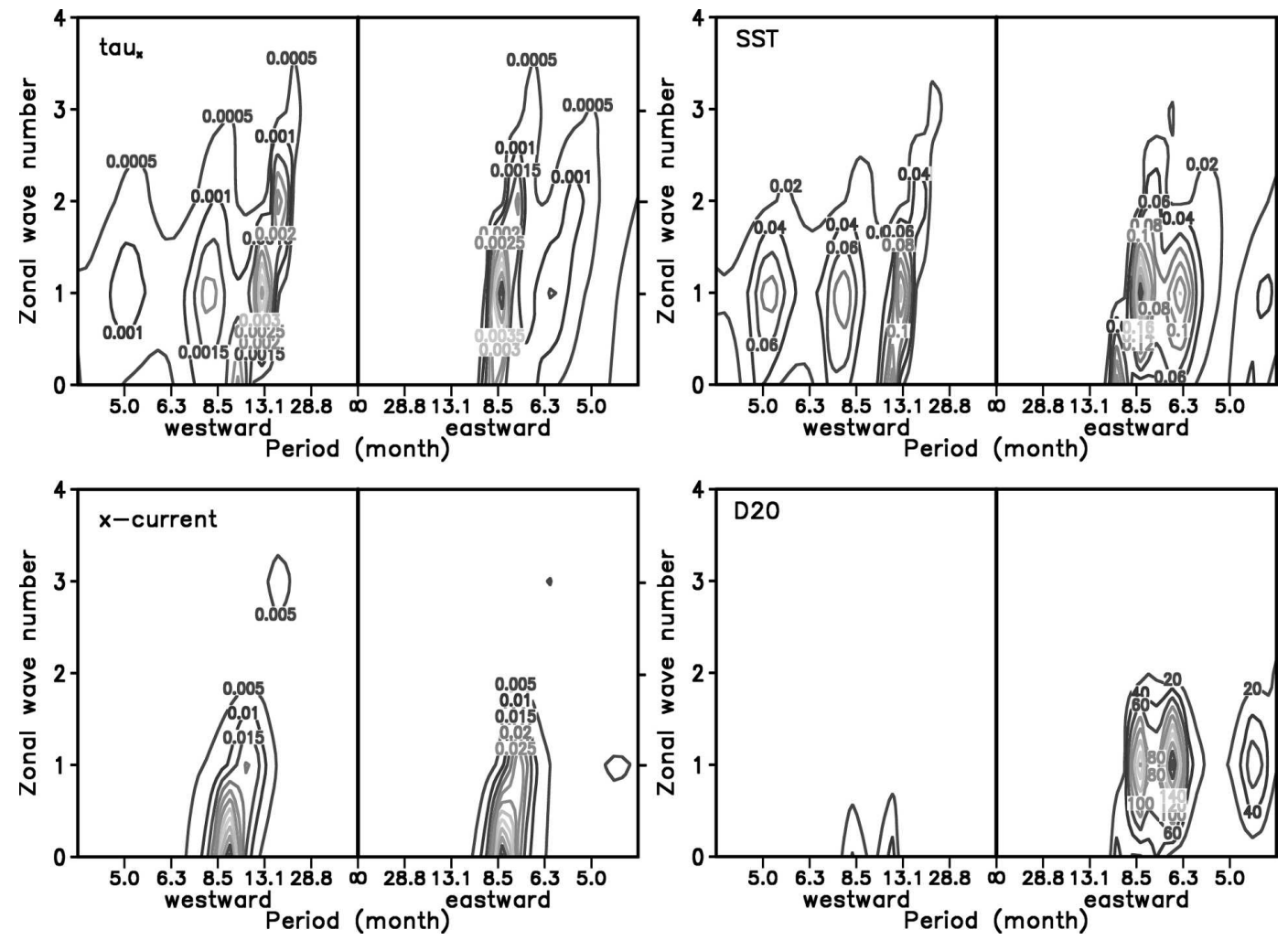

FIG. 10. The space-time power spectral density of the (a) ARPA 12-month high-pass-filtered SST, (b) zonal wind stress, (c) zonal current, and (d) $20^{\circ} \mathrm{C}$ isotherm anomalies along the equator.

which disfavors the resonance because forced and freepropagating waves interact more and air-sea feedbacks are stronger.

Thus, the fast mode being controlled by zonal advection of temperature, at $165^{\circ} \mathrm{E}$ and $180^{\circ}$ (the longitudes of the zonal current anomaly (ZCA) extrema for Exp0 and Exp2, respectively), $(\partial \bar{T} / \partial x)$ and $\bar{u}$ are the critical climatological parameters that determines its characteristics. At these longitudes, the mean upwelling prescribed in LODCA does not differ much from Exp0 and Exp2 (see Fig. 6). Interestingly at $165^{\circ} \mathrm{E},(\partial \bar{T} / \partial x)$ derived from Reynolds SST is equal to $(\partial \bar{T} / \partial x)$ at $180^{\circ}$ of ARPA, meaning that $u^{\prime}(\partial \bar{T} / \partial x)$ have a similar weight in both LODCA experiments at the location of maximum variability. On the other hand, in $\operatorname{Exp} 0, \bar{u}$ is $\sim 20$ $\mathrm{cm} \mathrm{s}^{-1}$ at $165^{\circ} \mathrm{E}$, meaning $\sim 40 \%$ weaker than $\bar{u}$ at $180^{\circ}$ for Exp2 (cf. Fig. 5). Thus, in Exp2, zonal advection by the mean current has a relatively stronger role than $u^{\prime}(\partial \bar{T} / \partial x)$ compared to Exp0. In addition, the nonlinear dynamical heating associated to anomalous zonal current, $u^{\prime}\left(\partial T^{\prime} / \partial x\right)$, along the equator is also relatively larger for Exp2 as explained above. Besides affecting the near-annual mode, the climatological state simulated by ARPA favors the nonlinear interaction of the near-annual mode with ENSO as examined below.
To confirm the privileged role of the climatological mean state in setting the conditions for the interaction between the near-annual mode and the ENSO mode, we carried out the experiment that consists in artificially favoring the zonal advective feedback versus the thermocline feedback in LODCA. To do so, LODCA is configured as in Exp0 but the climatological upwelling as derived from observations is replaced by the one derived from ARPA that is weaker (by a factor of $\sim 2$ on average). This experiment is called Exp0-Warpa. The results of this experiment are presented in Fig. 12. It shows that LODCA then sustains oscillations at a $\sim 2.9$-yr period instead of $4.9 \mathrm{yr}$ like in Exp0. In addition, the interaction between the ENSO mode and the near-annual mode as diagnosed by the spectrum of the first two principal components for the current of the SVD between wind stress and zonal current anomalies is enhanced as compared to Exp0 (cf. Fig. 8). Note that the mirror experiment consisting in prescribing the ARPA horizontal current climatology instead of the one derived from observation in a configuration similar to the Exp0 (experiment referred as Exp0-HCarpa, cf. Table 2) results in an annual ENSO (not shown). The interpretation is that the enhanced fast mode destabilizes the model ENSO mode, which is mostly driven by 
SVD mode 1 TXA (32\%), EXP0
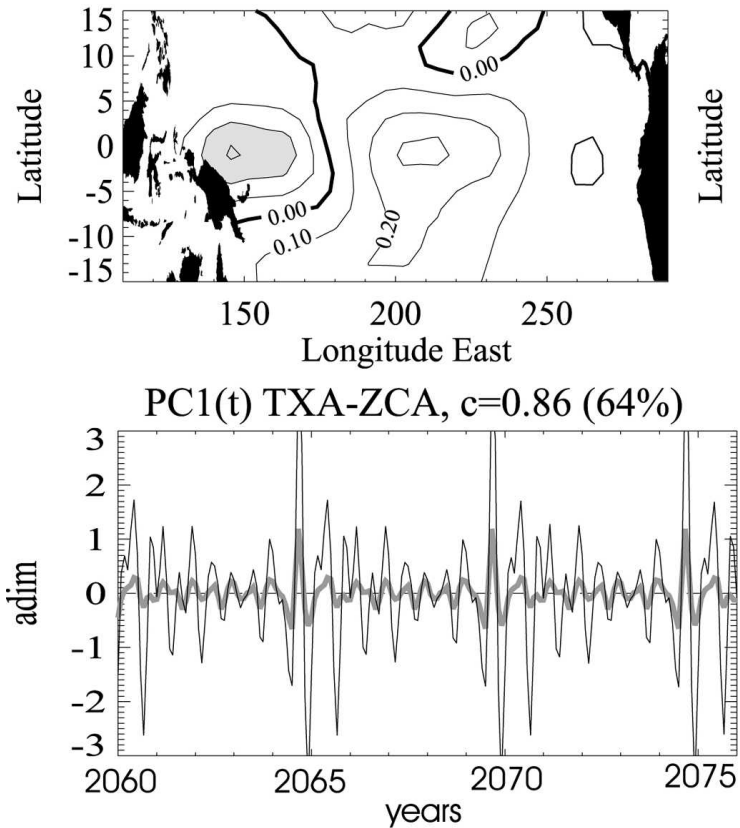

SVD mode 1 TXA (37\%), EXP2
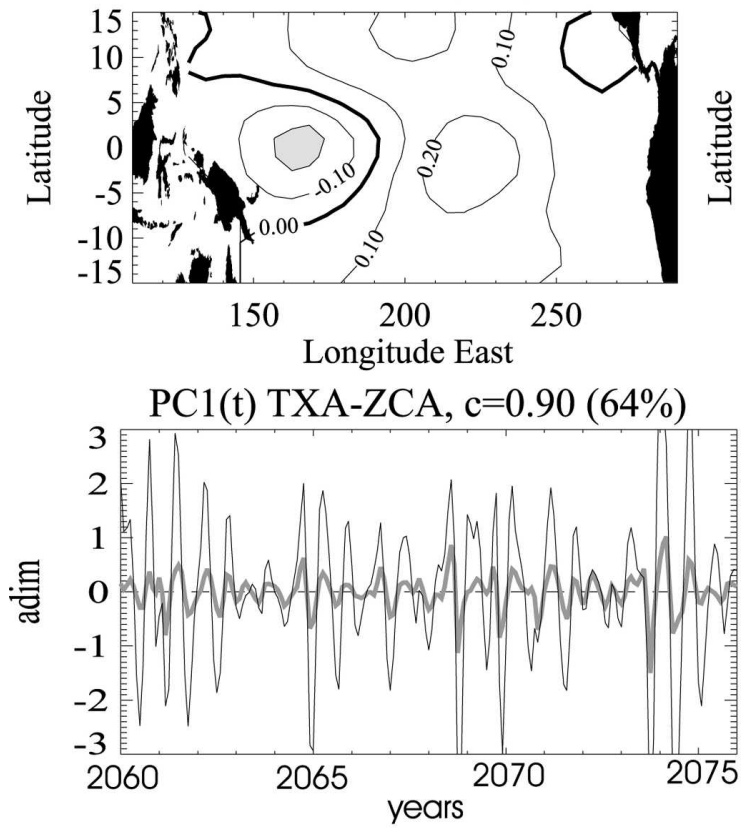

SVD mode 1 ZCA (43\%), EXP0
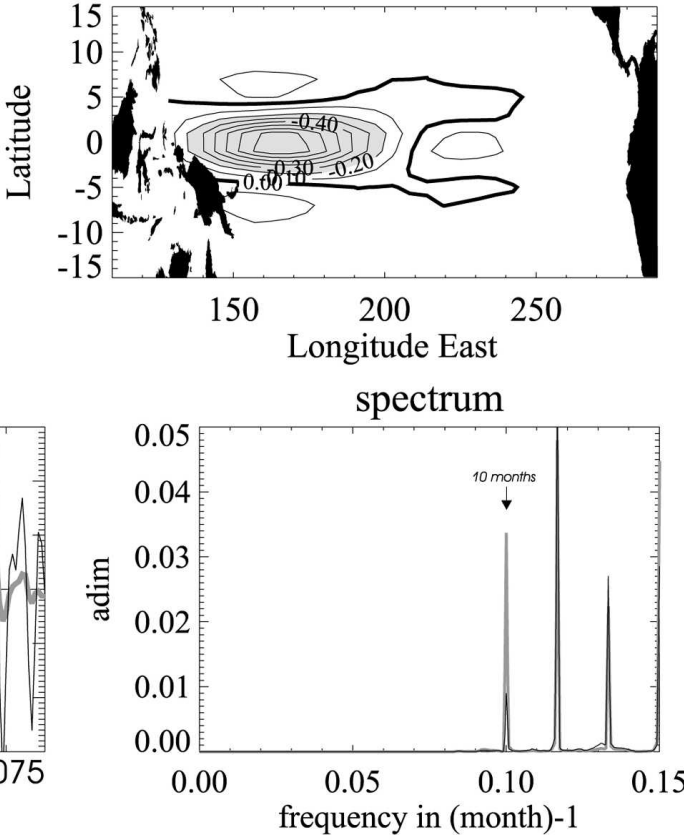

SVD mode 1 ZCA (47\%), EXP2
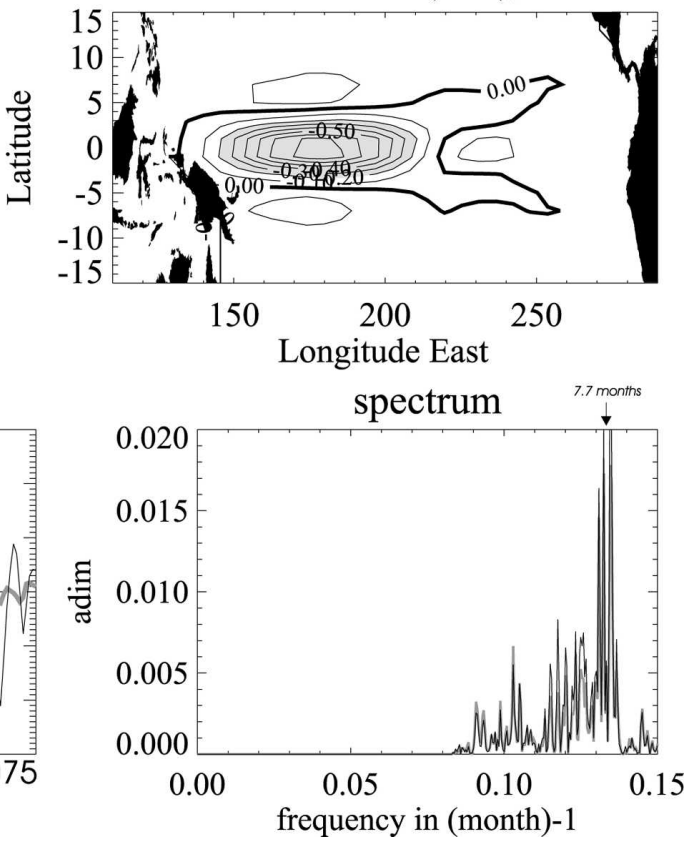

FIG. 11. Same as in Fig. 9 but for the experiments with LODCA: (top) Exp0 and (bottom) Exp2 (see Table 2 for the description of the experiments).

thermocline feedback in that configuration. In that sense, the impact of the seasonal cycle is such that an El Niño event is triggered every year in the model. At that stage it becomes difficult to infer any additional conclusion from this experiment because the stability of the system has changed dramatically due to an overenergetic seasonal cycle.

\section{c. Nonlinearities associated with the near-annual mode: Impact on the mean state}

Interactions between time scales take place through the nonlineraties of the coupled system. To further investigate the interactions of the near-annual mode, ENSO, and mean state in ARPA, we examine the 


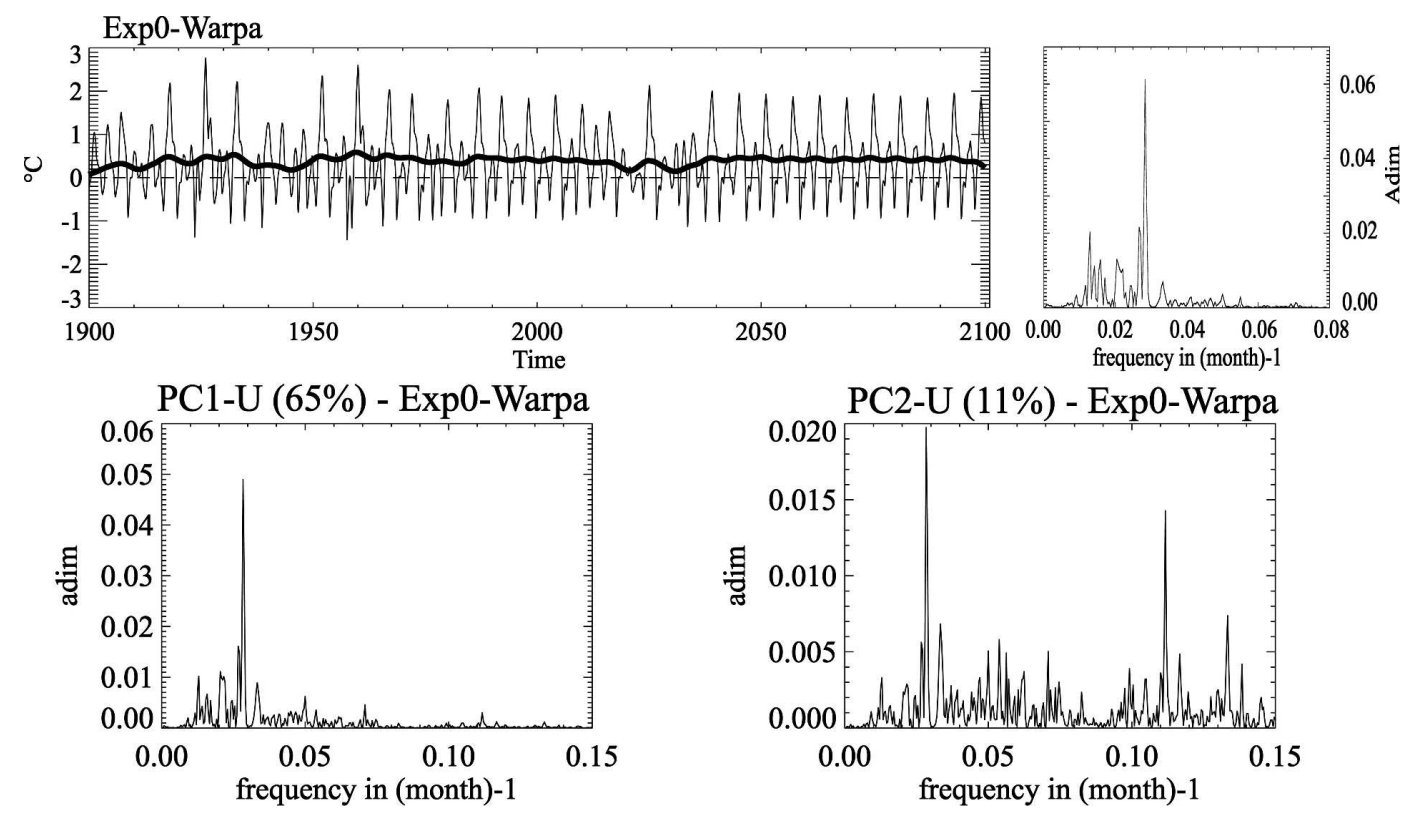

FIG. 12. Results for LODCA (Exp0-Warpa) (see Table 2). (top left) Time series of (thin full line) Niño-3 SST and (thick line) N3VAR indices, units are in ${ }^{\circ} \mathrm{C}$ for Niño-3 SST and in ${ }^{\circ} \mathrm{C}^{2}$ for N3VAR. (right) Associated Niño-3 SST frequency spectrum adimensionalized by the energy integrated over the whole frequency domain. (bottom) Spectra of zonal current time series for SVD mode (left) 1 and (right) 2 between the surface zonal current and wind stress anomalies. Spectra are adimensionalized by the energy integrated over the whole frequency domain. The percentage of explained variance of the modes is indicated at the top of each panel.

skewness of ENSO and of the near-annual mode. The skewness (White 1980) can yield physically meaningful patterns for the interpretation of the coupling between time scales. The skewness is a normalized third statistical moment. To avoid the large skewness created in case of small standard deviation, following An (2004), we compute the weighted skewness rather than the normalized skewness. The weighted skewness is defined as $m_{3} / m_{2}$ where $m_{k}=\sum_{i=1}^{N}\left(x_{i}-\bar{x}\right)^{k} / N ; x_{i}$ is the $i$ th observations, $\bar{x}$ is the mean, and $N$ is the number of observations. The skewness of the full SSTAs (Fig. 13a) indicates the regions where the model ENSO variability has asymmetric features. It can be viewed as a measure of the nonlinearity of ENSO (An and Jin 2004). Consistent with the results of CMTD (their Fig. 18), the pattern for SSTA is similar to the sum of the El Niño and La Niña composites of the model. The central and eastern equatorial Pacific is dominated by positive skewness, the western Pacific by negative skewness. This seesaw pattern reflects the fact that on average the cold events extend farther west than the warm events. The meridional structure also suggests an energy distribution on the baroclinic mode that depends on the phase of ENSO. The gravest (higher order) baroclinic mode(s) is associated to larger (finer) meridional scale being favored during the warm (cold) phases. Similar characteristics can be seen on the skewness map for the observed SSTAs (Fig. 13e) although observed SSTA skewness has a larger meridional scale and a larger (smaller) positive (negative) amplitude in the eastern (western) Pacific. These discrepancies are consistent with the differences between ARPA and observed climatologies (see section 4).

Interestingly the regions along the equator of negative SSTA skewness correspond to a maximum variability for the near-annual mode (Fig. 9). We now examine how the latter contributes to the ENSO asymmetry. To investigate this possibility, the skewness of the 12month high-pass-filtered zonal advection terms for ARPA is displayed in Figs. 13c-e. Results indicate that $-u^{\prime}\left(\partial T^{\prime} / \partial x\right)$ and $-\bar{u}\left(\partial T^{\prime} / \partial x\right)$ contribute more to SST cooling than warming in the western equatorial Pacific. By contrast, the skewness for $\left[-u^{\prime}(\partial \bar{T} / \partial x)\right]$ is mostly positive along the equator, but even in the central $\mathrm{Pa}$ cific where it reaches its maximum, it is smaller (by $\sim 30 \%$ ) than the skewness of the other two terms. According to Kang et al. (2004), the advection of the climatological mean SST gradient by the anomalous current is the driving term for the pure theoretical POB mode. The near-annual mode present in ARPA deviates from the POB mode by the contribution of $-u^{\prime}\left(\partial T^{\prime} / \partial x\right)$ and $-\bar{u}\left(\partial T^{\prime} / \partial x\right)$, which have a larger contribution than $\left[-u^{\prime}(\partial \bar{T} / \partial x)\right]$. Their negative skewness on average along the equator indicates that they con- 

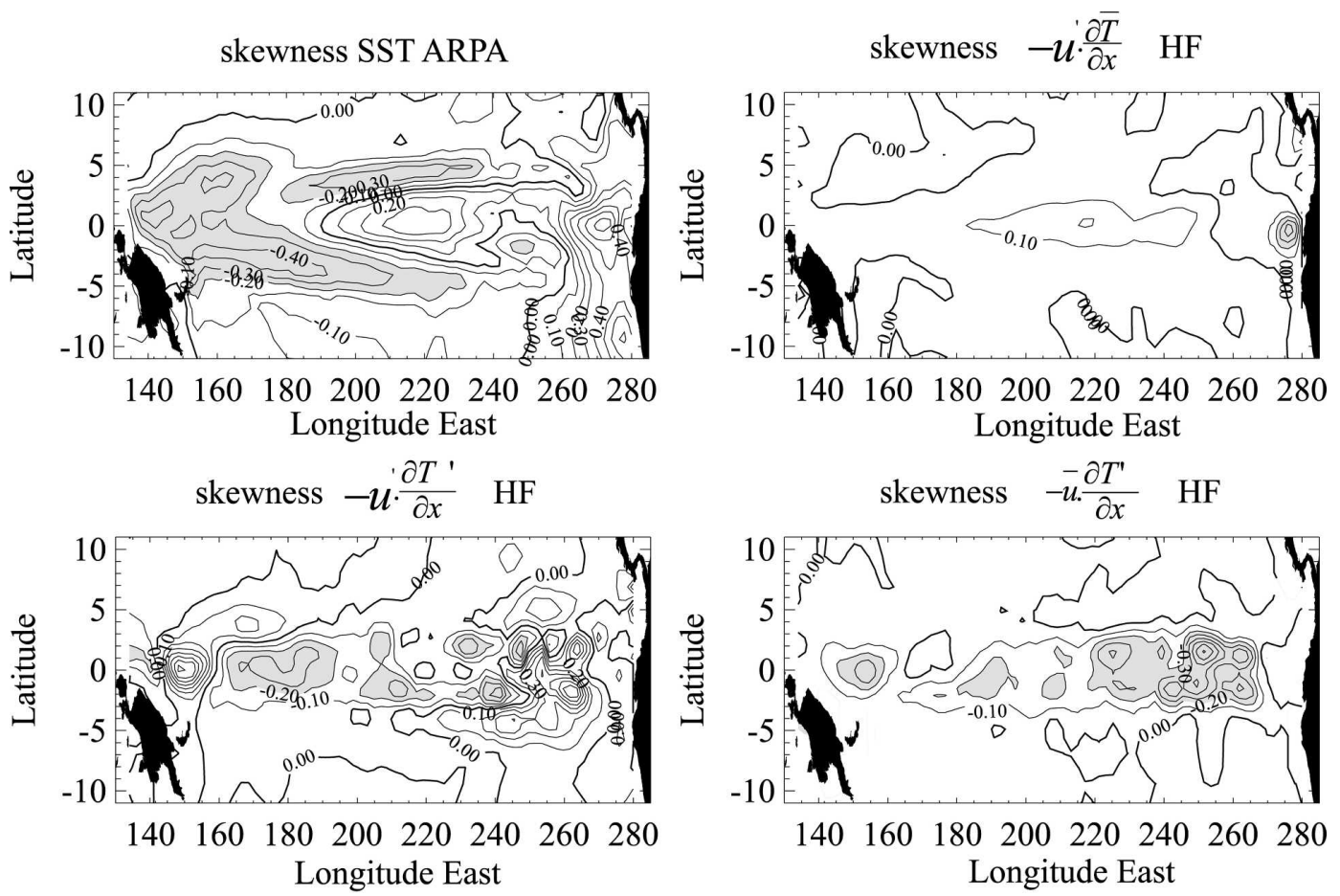

kewness SST OBS
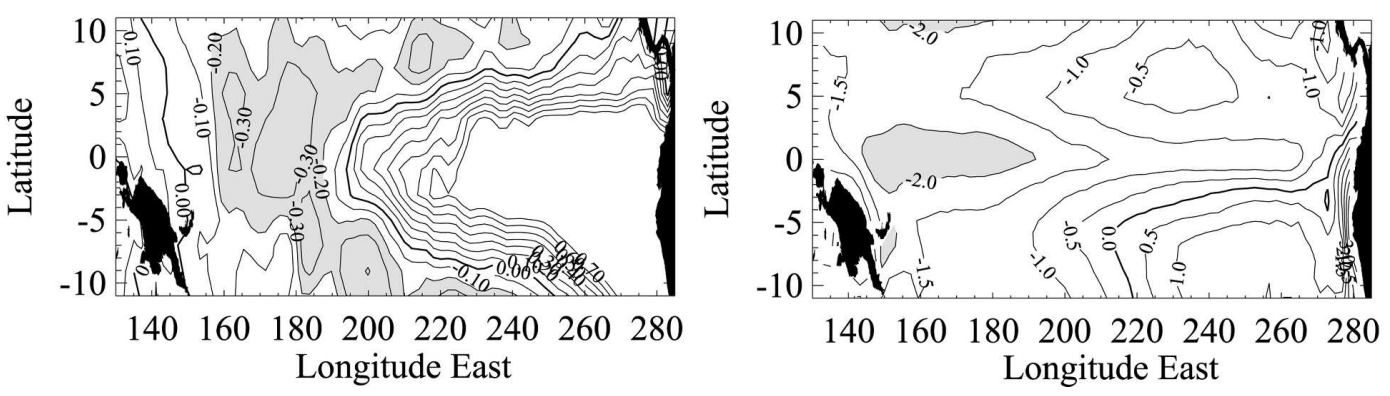

FIG. 13. (a) Skewness of full ARPA SSTAs, (b) 12-month high-pass-filtered advection of climatological temperature by anomalous zonal current, (c) 12-month high-pass-filtered nonlinear dynamical heating associated with the zonal current, (d) 12-month high-pass-filtered advection of anomalous temperature by climatological zonal current, (e) full observed SSTAs [Climate Analysis Center (CAC), 1970-2000], and (f) difference between mean ARPA SST and mean observed SST. Units are in ${ }^{\circ} \mathrm{C}$ for (a), (e), and (f) and $2 \times 10^{6}{ }^{\circ} \mathrm{C} \mathrm{s}^{-1}$ for the advection terms.

tribute more to SST cooling than warming. This is consistent with the cooler SST simulated in ARPA than in observations along the equator (see Fig. 13f).

Because in the LODCA experiments, the model variability does not feedback on the mean state (since it is prescribed), it is not possible to diagnose the mean state drift of the anomaly coupled model. However, the difference in skewness of the high-frequency SST anomalies between Exp2 and Exp0 (Fig. 14) indicates that in LODCA referring to the ARPA climatologies (Exp2), the fast mode contributes much more to the cooling in the western Pacific than in LODCA referring to the observed climatologies (Exp0), which supports the

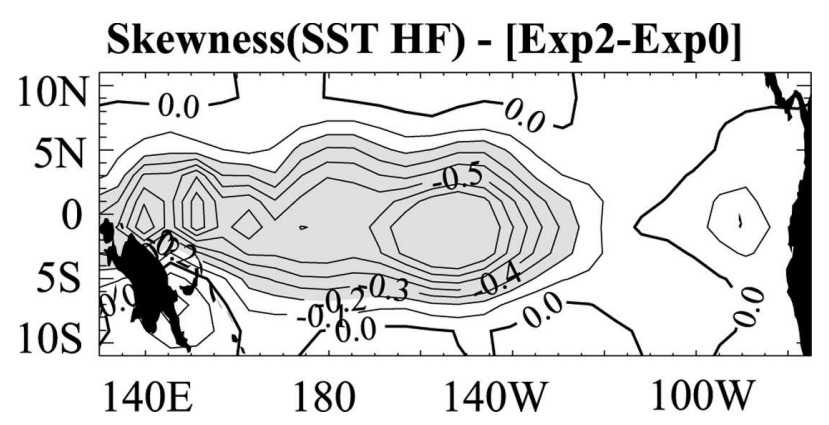

FIG. 14. The map of the difference in skewness of the 12-month high-pass-filtered SST anomalies between Exp2 and $\operatorname{Exp} 0\left({ }^{\circ} \mathrm{C}\right)$. 
above interpretation of the role of the near-annual mode in ARPA.

\section{Conclusions and perspectives}

The equatorial variability of a 260-yr full-physic CGCM simulation was investigated with a focus on the interaction between the ENSO mode and the nearannual mode. The model simulates an ENSO mode that oscillates at a dominant quasi-biennial frequency and an energetic near-annual mode that has an 8-month period. The vertical structure variability is first investigated. It shows that the model has more contributions of the high-order baroclinic mode than in reality. The presence of these slow high-order modes in the CGCM does not explain the period of the simulated ENSO, which is shorter than in reality. The climatological state of the CGCM is then analyzed in order to point out the biases that are most likely to explain why the model ENSO peaks at $\sim 2$ yr. The CGCM simulates equatorial trade winds that are too weakly responsible for the shallow thermocline in the western and central Pacific, which favors the contribution of the higherorder baroclinic modes. On the other hand, the offequatorial variability of the winds is associated with overenergetic westward climatological currents that tend to enhance the near-annual mode in the model consistent with the theory (Kang et al. 2004). The characteristics of the near-annual mode in the CGCM are described: it exhibits clear propagating characteristics in the 8-month period both in the zonal current and thermocline anomalies. The dominant pattern is best extracted from the principal component analysis of the zonal wind stress and the zonal current anomalies. The near-annual mode has maximum amplitude in the western Pacific and projects on the first three baroclinic modes.

Results of sensitivity experiments with an intermediate coupled model of the tropical Pacific demonstrate that the background climatology do set the observed time scales in the CGCM and determine the nature of the interaction between the ENSO mode and the nearannual mode. In particular, the climatological zonal currents and the reduced upwelling rate in the model are favorable to the development of the near-annual mode, which in turn destabilize the ENSO mode toward more activity in the biennial frequency band. The hypothesis of interaction between time scales (nearannual mode versus ENSO mode) through the impact of the mean state on the equatorial dynamics is consistent with the patterns of skewness for SST and highfrequency zonal advection of temperature. In particular, the negative skewness in the central-western Pacific for SST anomalies is associated to both the negative skewness of nonlinear zonal advection and the cold bias in the model. We suggest that the near-annual mode, ENSO mode, and mean climatological state interact in a constructive manner to produce the cold bias in the model: the near-annual mode destabilizes the ENSO mode, which leads to more frequent El Niño and La Niña events (dominant biennial variability). The asymmetry of the ENSO mode (as measured by the SST skewness) is modified due to both the enhanced cooling in the west through nonlinearities associated to the near-annual mode and to the inherent asymmetry of ENSO (An and Jin 2004). This reduces the zonal gradient of temperature across the equatorial Pacific and consequently the equatorial trade winds, which in turn produces the shallower thermocline than observed. The shallower thermocline is associated to an increased contribution of the higher-order baroclinic mode, which results in a specific response of the equatorial ocean to the wind forcing. In particular, the meridional scale of variability for SST is finer than in the observations (see Figs. 13a,e), as well as the wind response to these SST anomalies characterized by overenergetic anticyclonic atmospheric circulation off the equator [typical of a Gill (1980)'s type response to equatorially confined SST patch]. The latter are associated to the overenergetic westward climatological zonal current in the model that enhanced the zonal advective feedback and favors the near-annual mode activity.

Overall, our study points out to the need of improving the simulated mean state and seasonal cycle from CGCM. It confirms that the latter can have a large impact on the coupled modes of variability (Fedorov and Philander 2001). It is interesting to note that among the Intergovernmental Panel on Climate Change (IPCC) simulations, the ones that present the higherfrequency ENSO cycle than observed are the ones that have a weak east Pacific thermocline feedback loop (van Oldenborgh et al. 2005). It would be worth investigating the near-annual variability in these simulations and see if it is related to similar model biases. The paper proposes a simple way to diagnose the activity of this mode from the statistical relationship between wind stress and zonal current anomalies from the high-passfiltered outputs (see Fig. 9) but other techniques need to be used to better analyze the nonlinearities of the signals involved considering that its signature is much weaker than the ENSO mode. For instance, the fast mode activity is hardly detectable from Fourier analysis of the total SST. Because it is tightly linked to the zonal advective feedback, diagnostics from zonal current anomalies should provide better insights and allow for the isolation of the pure ENSO cycle from the near- 
annual signal. Regarding this topic, further studies need to be pursued with the difficult task of clarifying the specific role of the various component of the intraseaonal variability on the ENSO cycle. For instance, the coupling between western wind bursts (WWB) and ENSO as suggested by Yu et al. (2003) suggests that the ENSO cycle inherently has an ability to trigger itself. The near-annual mode superimposes to this stochastic system, which renders the coupled system even more complex.

At this stage, it is interesting to note that the presence of this fast mode depends on the mean state conditions, which are themselves influenced by the ENSO modulation (Rodgers et al. 2004; CMTD). This may explain why the near-annual activity has been so difficult to observe in nature (Jin et al. 2003). In addition to its period that is close to one year and its SST signature, which is weak, it is likely that the near-annual activity is subject to low-frequency modulations like ENSO that may impact its characteristics (dominant period, amplitude, etc.). This will have to be elucidated in other model simulations and/or observations.

Acknowledgments. The authors thank the two anonymous reviewers for their comments. S.-I. An has been supported by the SRC program of Korea Science and Engineering Foundation, and the Brain Korea 21 project. This work also benefited from stimulating discussions with Yves duPenhoat.

\section{REFERENCES}

AchutaRao, K., and K. Sperber, 2002: Simulation of the El NiñoSouthern Oscillation: Results from the Coupled Model Intercomparison Project (CMIP). Climate Dyn., 19, 191-209.

_- and Coauthors, 2004: An appraisal of coupled climate model simulations. Lawrence Livermore National Laboratory Tech. Doc., 197 pp.

An, S. I., 2004: Interdecadal changes in the El Niño-La Niña asymmetry. Geophys. Res. Lett., 31, L23210, doi:10.1029/ 2004GL021699.

— , and F.-F. Jin, 2000: An eigen analysis of the interdecadal changes in the structure and frequency of ENSO mode. Geophys. Res. Lett., 27, 2573-2576.

—- and B. Wang, 2000: Interdecadal change in the structure of the ENSO mode and its impact on the ENSO frequency. $J$. Climate, 13, 2044-2055.

— , and F.-F. Jin, 2001: Collective role of thermocline and zonal advective feedbacks in the ENSO mode. J. Climate, 14, 34213432 .

— Climate, 17, 2399-2412.

Antonov, J., S. Levitus, T. P. Boyer, M. Conkright, T. O'Brien, and C. Stephens, 1998: Temperature of the Pacific Ocean. Vol. 2, World Ocean Atlas 1998, NOAA Atlas NESDIS 28, 166 pp.

Blanke, B., J. D. Neelin, and D. Glutzler, 1997: Estimating the effect of stochastic wind stress forcing on ENSO irregularity. J. Climate, 10, 1473-1486.

Cibot, C., E. Maisonnave, L. Terray, and B. Dewitte, 2005: Mechanisms of tropical Pacific interannual-to-decadal variability in the ARPEGE/ORCA global coupled model. Climate Dyn., 24, 823-842.

Déqué, M., C. Dreveton, A. Braun, and D. Cariolle, 1994: The climate version of ARPEGE/IFS: A contribution to the French community climate modeling. Climate Dyn., 10, 249266.

Dewitte, B., 2000: Sensitivity of an intermediate coupled oceanatmosphere model of the tropical Pacific to its oceanic vertical structure. J. Climate, 13, 2363-2388.

_ and C. Périgaud, 1996: El Niño-La Niña events simulated with Cane and Zebiak's model and observed with satellite or in situ data. Part II: Model forced with observations. J. Climate, 9, 1188-1207.

_ G. Reverdin, and C. Maes, 1999: Vertical structure of an OGCM simulation of the equatorial Pacific Ocean in 19851994. J. Phys. Oceanogr., 29, 1542-1570.

Fedorov, A. V., and S. G. Philander, 2001: A stability analysis of tropical ocean-atmosphere interactions: Bridging measurements and theory for El Niño. J. Climate, 14, 3086-3101.

Fichefet, T., and M. A. Morales Maqueda, 1997: Sensitivity of a global sea ice model to the treatment of ice thermodynamics and dynamics. J. Geophys. Res., 102 (C6), 12 609-12 646.

Gill, A., 1980: Some simple solutions for heat-induced tropical circulation. Quart. J. Roy. Meteor. Soc., 106, 447-462.

Guilyardi, E., and Coauthors, 2004: Representing El Niño in coupled ocean-atmosphere GCMs: The dominant role of the atmospheric component. J. Climate, 17, 4623-4629.

Hayashi, Y., 1977: Space-time power spectral analysis using the maximum entropy method. J. Meteor. Soc. Japan, 55, 415420.

Hirst, A. C., 1986: Unstable and damped equatorial modes in simple coupled ocean-atmosphere models. J. Atmos. Sci., 43, 606-630.

Jin, F.-F., 1997: An equatorial ocean recharge paradigm for ENSO. Part II: A stripped-down coupled model. J. Atmos. Sci., 54, 830-846.

_, J.S. Kug, S. I. An, and I. S. Kang, 2003: A near-annual coupled ocean-atmosphere mode in the equatorial Pacific Ocean. Geophys. Res. Lett., 30, 1080, doi:10.1029/ 2002 GL015983.

Kang, I.-S., J.-S. Kug, S.-I. An, and F.-F. Jin, 2004: A near-annual Pacific Ocean basin mode. J. Climate, 17, 2478-2488.

Kirtman, B., and P. S. Schopf, 1998: Decadal variability in ENSO predictability and prediction. J. Climate, 11, 2804-2822.

Moon, B.-K., S.-W. Yeh, B. Dewitte, J.-G. Jhun, I.-S. Kang, and B. Kirtman, 2004: Vertical structure variability in the equatorial Pacific before and after the Pacific climate shift of the 1970s. Geophys. Res. Lett., 31, L03203, doi:10.1029/2003GL018829.

Neelin, J. D., and F.-F. Jin, 1993: Modes of interannual tropical ocean-atmosphere interaction-A unified view. Part II: Analytical results in the weak-coupling limit. J. Atmos. Sci., 50, 3504-3522.

Périgaud, C., C. Cassou, B. Dewitte, L.-L. Fu, and D. Neelin, 2000: Using data and intermediate coupled models for seasonal-tointerannual forecasts. Mon. Wea. Rev., 128, 3025-3049.

Philander, S. G., 1990: El Niño, La Niña and the Southern Oscillation. Academic Press, $289 \mathrm{pp}$.

Rodgers, K. B., P. Friederichs, and M. Latif, 2004: Decadal ENSO 
amplitude modulations and their effect on the mean state. $J$. Climate, 17, 3761-3774.

Ropelewski, C. F., M. S. Halpert, and X. Wang, 1992: Observed tropospheric biennial varaiability and its relationship to the Southern Oscillation. J. Climate, 5, 594-614.

Roullet, G., and G. Madec, 2000: Salt conservation, free surface and varying volume: A new formulation for ocean GCMs. $J$. Geophys. Res., 105, 23 927-23942.

Terray, L., E. Sevault, E. Guilyardi, and O. Thual, 1995: OASIS 2.0, user's guide and reference manual. CERFACS Tech. Rep. TR/CMGC/95-46.

Tourre, Y. M., Y. Kushnir, and W. B. White, 1999: Evolution of interdecadal variability in sea level pressure, sea surface temperature, and upper ocean temperature over the Pacific Ocean. J. Phys. Oceanogr., 29, 1528-1541.

van Oldenborgh, G. J., S. Y. Philip, and M. Collins, 2005: El Niño in a changing climate: A multi-model study. Ocean Sci., 1, $81-95$.

Wang, B., and S.-I. An, 2001: Why the properties of El Niño changed during the late 1970s. Geophys. Res. Lett., 28, 37093712.

White, H. G., 1980: Skewness, kurtosis and extreme values of Northern Hemisphere geopotential heights. Mon. Wea. Rev., 108, 1446-1455.

Yeh, S.-W., B. Dewitte, J.-G. Jhun, and I.-S. Kang, 2001: The characteristic oscillation induced by coupled processes between oceanic vertical modes and atmospheric modes in the tropical Pacific. Geophys. Res. Lett., 28, 2847-2850.

Yu, L., R. A. Weller, and W. T. Liu, 2003: Case analysis of a role of ENSO in regulating the generation of westerly wind bursts in the western equatorial Pacific. J. Geophys. Res., 108, 3128, doi:10.1029/2002JC001498.

Zebiak, S. E., and M. A. Cane, 1987: A model El Niño-Southern Oscillation. Mon. Wea. Rev., 115, 2262-2278.

Zhang, R.-H., L. M. Rothstein, and A. J. Busalacchi, 1999: Interannual and decadal variability of the subsurface thermal structure in the Pacific Ocean. Climate Dyn., 15, 703-717. 